\title{
Delay of Gratification in Preschool Children Following Access to Print and Mobile Electronic Media
}

\author{
By \\ (C) 2018
}

Gideon Peter Naudé

B.A., University of Kansas, 2015

Submitted to the graduate degree program in Applied Behavioral Science and the Graduate Faculty of the University of Kansas in partial fulfillment of the requirements for the degree of Master of Arts.

Derek D. Reed, Ph.D. Chairperson

Claudia L. Dozier, Ph.D. Committee Member

Todd L. McKerchar, Ph.D. Committee Member

Date Defended: 18 April 2018 
The thesis committee for Gideon Peter Naudé certifies that this is the approved version of the following thesis:

\section{Delay of Gratification in Preschool Children Following Access to Print and Mobile Electronic Media}

Derek D. Reed, Ph.D.

Date Approved: April 30, 2018 


\begin{abstract}
Mobile electronic media is ever-present in the lives of young children and an examination of the behavioral byproducts following the use of these modalities is timely. The present study assessed the extent to which mobile electronic and print media interact with operant demand and delay of gratification in preschool children. Participants were six boys $\left(M_{a g e}=3.82\right.$ years, $\left.\mathrm{SD}=0.24\right)$ recruited from a university-run preschool. In Phase 1, participants allocated responses to buttons providing access to either a print book at a fixed-price (FR-1) or an e-book containing identical stimuli available at increasing prices (FR5 - FR200) to examine substitution-like effects. In Phase 2, across 9 - 15 sessions, participants received access to either the print book, the e-book, or a fast-paced interactive tablet game, 3 -5 times each in a randomized sequence; each engagement was immediately followed by a delay of gratification task (i.e., the Marshmallow Test). In this task, participants could consume a single piece of preferred edible at any point or wait $5-10$ min to receive two pieces. Delay of gratification was longest for all participants following access to print media. We discuss lower wait times following mobile electronic media conditions within the conceptual frameworks of escape from rich-to-lean transitions, reinforcer pathologies, and behavioral momentum.
\end{abstract}




\section{Table of Contents}

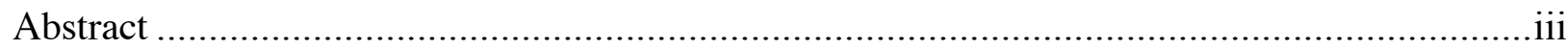

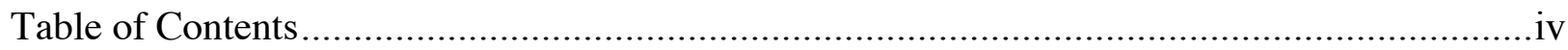

Delay of Gratification in Preschool Children Following Access to Print and Mobile Electronic

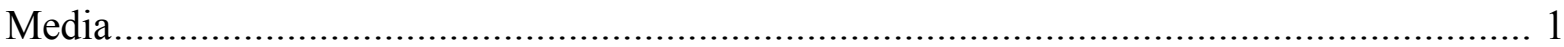

Electronic Media in Teaching and Therapeutic Contexts ............................................ 1

Risks Associated with Excessive Childhood Exposure to Electronic Media........................... 2

Review of the Literature on Children's Tolerance to Delays............................................. 3

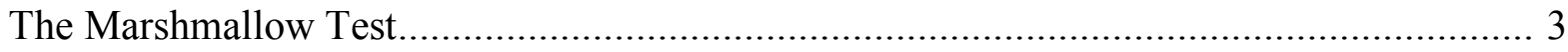

Interactions Between Age, Delays, and Reinforcer Magnitude ................................. 7

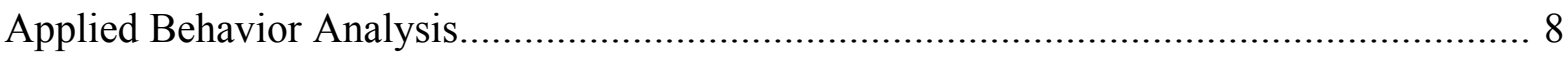

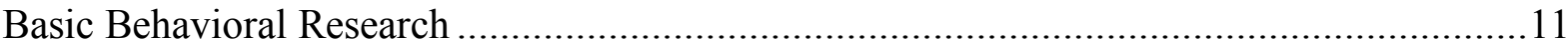

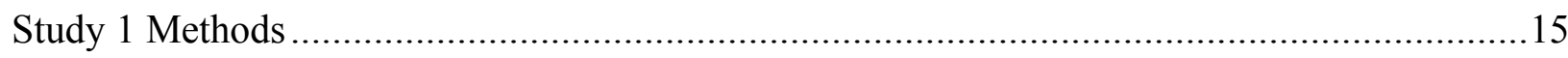

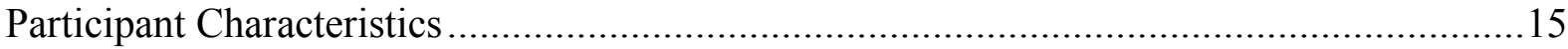

Reliability and Procedural Fidelity ...................................................................... 15

Operant Demand for e-Book Engagement ............................................................ 16

Preference for Visual Stimuli...................................................................... 16

Competing Reinforcer Assessment ........................................................... 18

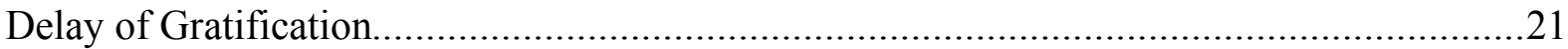

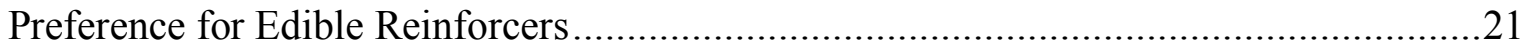

Modality Access and Delay of Gratification Assessment ...........................................24

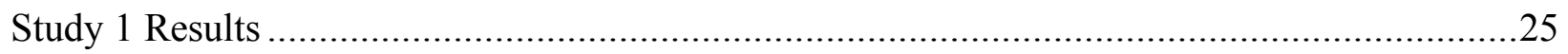




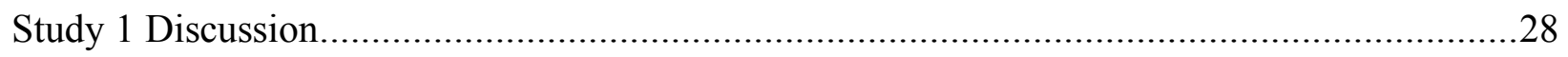

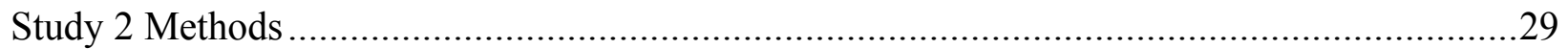

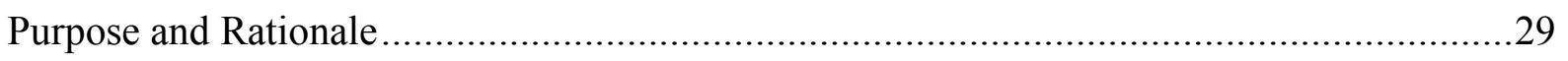

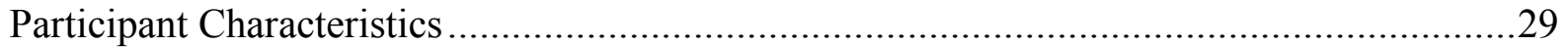

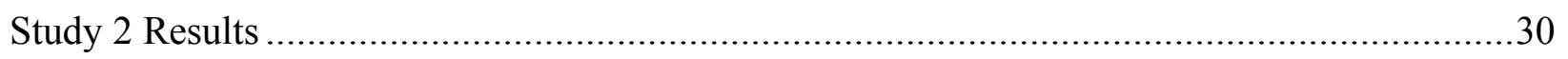

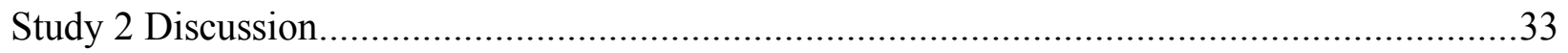

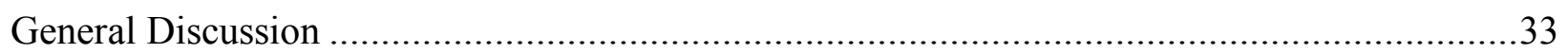

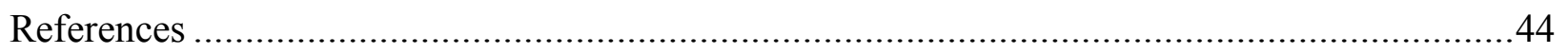

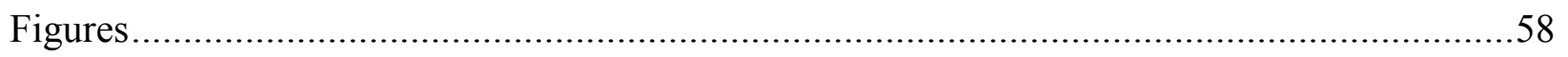

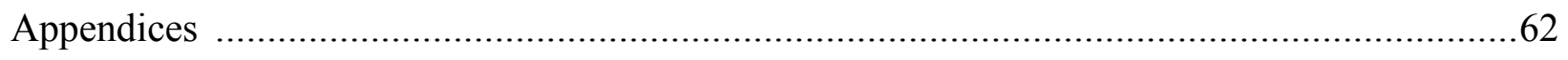


Delay of Gratification in Preschool Children Following Access to

Print and Mobile Electronic Media

Mobile electronic media (MEM) such as tablets and smartphones has become increasingly present in the lives of young children (American Academy of Pediatrics, 2013; Pew Internet and American Life project, 2017; Rideout \& Hamel, 2006; Rideout \& Saphir, 2011) with research indicating that $30-50 \%$ of preschool age children $(2-5$ years $)$ use either a tablet or a smartphone for at least $30 \mathrm{~min}$ a day (Duch, Fisher, Ensari, \& Harrington, 2013). Indeed, numerous studies have demonstrated a strong correlation between parental use of MEM and the time spent by children on the same devices (Bleakley, Jordan, \& Hennessy, 2013; Lauricella, Wartella, \& Rideout, 2015; Rideout \& Hamel, 2006). While MEM has demonstrated notable utility under certain contexts (LeBlanc \& Coates, 2003; McQueen, Cress, \& Tothy, 2012), a direct behavioral assessment of the impact of this type of media on the behavior of young children is timely and of crucial importance.

Screen-based technologies that advertise educational benefits like word-learning, creativity, and other areas of cognitive development are ever-present in the child-focused marketplace (Burke \& Marsh, 2013; Shuler, Levine, \& Ree, 2012). Parents, caregivers, educators, and service providers have taken note of the rapidly developing technologies, employing these devices in many areas in the lives of young children (Maich \& Hall, 2016). For example, mobile devices such as tablets and smartphones are used with increasing frequency to divert children's attention during medical procedures (McQueen, Cress, \& Tothy, 2012). Therapists and educators providing services to children frequently make use of iPads, tablets, and other screen media in the context of video modeling (Charlop-Christy, Le, \& Freeman, 2000; LeBlanc \& Coates, 2003; Mineo, Ziegler, Gill, \& Salkin, 2009). Furthermore, due to the 
increasing use of screen-based technologies among individuals with intellectual and developmental disabilities (IDD; Carey, Friedman and Bryan, 2005; Jameson et al., 2012), these technologies are frequently identified as high-preferred reinforcers and, as such, are also commonplace in therapeutic residential settings (Achmadi et al., 2012; Kagohara et al., 2013; Neely, Rispoli, Camargo, Davis, \& Boles, 2013; Ramdoss et al., 2011).

While children's exposure to types of MEM has demonstrated clear utility within certain contexts, there is evidence that limiting children's access to screen media is associated with lowered problems of attention, fewer sleep disturbances, and a reduced risk of obesity (Kondo et al., 2012; Ross, Dowda, Saunders, \& Pate, 2013). Several recent investigations have identified young children's frequent use of MEM as a potential contributor to delays in the development of fundamental motor skills (Cadoret, Bigras, Lemay, Lehrer, \& Lemire, 2016; Lin, Cheng, Chen, Chen, \& Yang, 2015) - a concern in its own right due to increasing rates of pre-diabetic conditions in youth (Dutra, Kauffman, Pretto, \& Albernaz, 2016; Ferrari et al., 2015). Despite MEM being a relatively new "issue" in young children, the recurrent use of mobile screen media shares several similarities to television viewing. Young children's television viewing may be termed a passive process relative to engaging in an interactive game on an $\mathrm{iPad} / \mathrm{tablet}$, however, both lack features of human interaction communicated through eye contact, body gestures, and responsive voice inflections (Patrikakou, 2016). Further, these technologies are increasingly used to keep children occupied during travel, eating out, and daily routines (Radesky et al., 2014).

One of several concerns raised by this use of MEM is that it may easily displace caregiver-child activities centered on language and play (Kirkorian, Pempek, Murphy, Schmidt, \& Anderson, 2009), which are crucial to young children's development and later success. In their groundbreaking longitudinal examination of language exposure in the lives of young children, 
Hart and Risley (1995) presented evidence that the types of verbal interactions between caregivers and young children was a strong determinant of later academic success. Further, the authors found that the "word gaps" were pronounced between socioeconomic categories, such that children of professional parents were exposed to 20 million more words by the age of 3 than children from low-income families. As a corollary, there is also research to suggest that lowincome families engage in more screen time (e.g., television and MEM) than average working class or professional families (Anderson, Economos, \& Must, 2008; Carson, Spence, Cutimisu, \& Cargill, 2010; Ribner, Fitzpatrick, \& Blair, 2017; Tandon et al., 2012) - a finding compounded by evidence suggesting screen time frequently displaces verbal exchanges between caregivers and young children (Kirkorian, Pempek, Murphy, Schmidt, \& Anderson, 2009; Pempek, Kirkorian, \& Anderson, 2014). Toward this end, activities reducing the frequency of verbal exchanges between caregivers and young children should warrant a careful behavioral examination.

From early childhood, many children of both typical and non-typical development have had only minimal experience tolerating delays in the absence of digital devices (Prensky, 2001) such as digital tablets and smart phones. It appears that now, in a high-speed age where exposure and tolerance to delay is becoming less and less common, there exists a need to reexamine contemporary determinants of self-control in young children. In the early 1960s, Walter Mischel began his seminal research on self-control and delay of gratification (DG). Recruiting participants with a modal age of 4 years from Stanford University's Bing Nursery School, Mischel initially assessed preference for pairs of reinforcers at varying delays and magnitudes. Mischel's early methods involved simply asking the child to indicate her/his preference in a booklet (Logue, 1988; Mischel, 1966). 
Given their curiosity about children's behavior during the delays to the larger (or more preferred) reinforcers, Mischel and Ebbesen (1970) initiated a long-running series of experiential DG experiments that involved real reinforcers and real delays. These experiments were constructed around a choice paradigm consisting of essentially two options: receive a lesspreferred reinforcer immediately or experience a delay in order to receive a more-preferred reinforcer. The commodities used in these studies consisted of edible and tangible reinforcers that varied in either child preference or magnitude. As an example, a child in the experimental setting could engage with a less-preferred set of toys at any point in the experiment, or withstand a delay ranging from $10-20 \mathrm{~min}$ in order to access the more-preferred set of toys. Similarly, a child could consume a less-preferred edible at any time or could wait for the experimenter to return and receive the more-preferred edible. In other cases, researchers offered choice of one type of highly-preferred reinforcer, with a greater quantity delivered upon withstanding the full duration of the delay. Researchers then assessed the child's preference for either two edible reinforcers or sets of tangible leisure items and explained to the child that $\mathrm{s} / \mathrm{he}$ (the researcher) would be leaving the room for a period of time. The child received the instruction that emitting a specific operant (e.g., sounding a bell) prior to the full duration of the delay that would result in the researcher's return and receipt of the less-preferred or smaller quantity of the reinforcers. Withstanding the full duration of the delay, however, would result in access to the reinforcer that was more-preferred or greater in magnitude.

Longitudinal data on the children who participated in these experiential DG experiments revealed clear and robust differences in long-term outcomes between children who did and did not delay gratification (Mischel, Ebbesen, Raskoff Zeiss, 1972; Mischel, Shoda, \& Peake, 1988; Mischel, Shoda, \& Rodriguez, 1989). In particular, adolescents who as children in the studies 
chose to wait the 15-20 min rather than consume the single immediately available reinforcer or settle for the less-preferred set of leisure items, later rated their social and cognitive behaviors higher, demonstrated better scores on college entrance exams, had lower body mass indexes, were rated by parents and caregivers as having better self-control, and being more tolerant of frustrating environmental conditions than those participants who chose the immediately available reinforcer. In later adolescence, these same participants produced higher Scholastic Aptitude Test (SAT) scores and, as adults, reported greater job and marital satisfaction (Shoda, Mischel, \& Peake, 1990). Mischel continued this line of research for the next several decades using what is now commonly referred to as the classic Marshmallow Test (for a complete synthesis of this work, see Mischel, 2014), assessing children's preference for two pieces of an edible reinforcer available after a delay, or a single piece available at any time prior to the end of the delay. This behavioral approach to examining DG approximates Navarick's (1986) behavior analytic definition of impulsivity: "the choice of an immediate, small reinforcer over a delayed, large reinforcer" (p. 343).

Over the decades following the initial Marshmallow Test experiments, Mischel and colleagues assessed a number of methods aimed at reducing the bias toward immediacy by shifting attentional mechanisms toward the delayed reinforcer (see Mischel \& Ebbesen, 1970; Mischel, Ebbesen, \& Raskoff Zeiss, 1972). A number of experiments assessed wait times when (a) only the less-preferred, (b) only the high-preferred, or (c) both reinforcers were visible to the child during the delay period; the rationale being that directing attention to the reinforcers would help to bridge the delay and facilitate longer wait times. The findings contradicted the hypothesis in that children's wait times were much shorter when both the rewards were exposed compared to trials in which only the bell that summoned the experimenter's return was present. In a related 
set of experiments, children were cued to think about the delayed reward, extending the hypothesis that attention directed toward the more-preferred reinforcer would reduce the subjective value of the immediately-available reinforcer.

The notion that instructing children to think about the rewards would result in better demonstrations of DG was undermined to a large degree by findings that demonstrated the contrary: when instructed to think about the reinforcers, children demonstrated considerably lower wait times. However, when instructed by the experimenter to think about "fun" distracting thoughts, all children waited for longer than $10 \mathrm{~min}$. These findings suggest cueing attentional mechanisms away from the present facilitated greater DG than when children attended to the actual reinforcing commodities. The authors note support for this position in that, during the delay, the children who demonstrated longest wait times engaged in various topographies that could be described as diversions: covering their eyes with their hands, singing, engaging in quiet verbalizations, inventing games with their fingers or feet, and even attempting to sleep (Mischel, Shoda, \& Rodriguez, 1989).

The experiments described above centered on attention directed toward the reinforcers themselves, and not the outcome of withstanding the full duration of the delay. As such, a subsequent series of experiments sought to evaluate the effects of using realistic images of the reinforcers presented on slides on children's DG (Mischel \& Moore, 1973). Contrary to the experiments that demonstrated that children demonstrated lower wait times during exposure to the actual reinforcers, when exposed to images of the reinforcers, the children waited considerably longer. Interestingly, when tasked with thinking about images of the actual rewards, rather than the rewards themselves, children waited nearly 20 min. Covert verbalization of conditioned reinforcers (i.e., images of the reinforcers, rather than the actual reinforcers) 
appeared to contribute to longer wait times. The authors described the covert behavior of tacting the properties of the actual stimulus as a behavior that may elicit an arousing action sequence (a chain of operants; e.g., consuming an edible reinforcer, or engaging with a leisure item), whereas tacting abstract properties of the stimulus (i.e., an image of the reinforcer) may have a suppressive effect on the aforementioned action sequence by serving as a cue for the contingency associated with delaying gratification (Mischel et al., 1989, p. 935).

There is evidence to suggest that, during preschool age, children experience certain maturational periods during which reinforcer dimensions like immediacy and/or magnitude interact (Garon, Johnson, \& Steeves, 2011). In a study examining preschoolers' choices between a single immediately available tangible item (one sticker) and two to five stickers at the end of an activity, Lemmon and Moore (2007) found that the 29 participants in the 4-year-old group more frequently opted to withstand the delay as reward magnitude increased. This effect of reward magnitude did not occur among the 26 participants in the 3 -year-old group, suggesting that elements of more optimal temporal choice may begin to emerge within the behavioral repertoires of older preschool children (Garon, Johnson, \& Steeves, 2011). Important to note is that the participants in this study were exposed to only a single delay length (i.e., the activity), thereby precluding a parametric comparison of- and possible interactions between- delay, reinforcer magnitude, and age. Ito, Saeki, and Sorama (2009) manipulated both reinforcer magnitude and length of the delay in children aged 5-6. Interestingly, the results indicate that participants in the younger group demonstrated greater sensitivity to variation in reinforcer magnitude, whereas the older group was more sensitive to variations in delay.

Despite the aforementioned studies employing developmental or cognitive explanations for children's DG, behavior analysis has a rich history in conceptualizing DG within a more 
parsimonious operant framework. An operant approach to DG - via decades of behavior analytic study - provides unique tools and analyses that could spur the necessary research in evaluating claims of MEM moderating role in developmental trajectories. For example, several studies have examined the effects of providing brief rules and other mediating activities on young children's DG (Gokey, Wilder, Welch, Collier, \& Mathisen, 2013; Whiting \& Dixon, 2015). Binder, Dixon, and Ghezzi (2000) used progressive delays in combination with intervening speaking tasks in order to train self-control behaviors in three preschool children diagnosed with attention deficit hyperactivity disorder (ADHD). The authors provided each child with the choice of a smaller-sooner reward (SSR) or a larger-later reward (LLR), delivered after an increasing delay. The authors introduced the intervening speaking task in the event that the child selected the larger reward and consisted of either reciting a brief rule ("If I wait a little longer, I will get..."), or labeling images depicted on index cards. While both intervening tasks were successful in mediating delays to the LLR, no one component outperformed the other, suggesting that the mere availability of an intervening activity can effectively shift behavior toward choices that result in delayed, yet more optimal outcomes. Indeed, the activities compared by Binder et al. shared similarities with those resulting in longer wait times in the Mischel et al studies. For example, participants who tended to wait for longer durations often engaged in behaviors like, singing, verbalizing quietly, and/or playing games with their hands or feet, rather than directly attending to the properties of the SSR (Mischel, Shoda, \& Rodriguez, 1989). Delay-mediating behaviors, however, are not a uniquely human phenomenon. Non-human organisms will engage in grooming, as well as polydipsia (i.e., excessive water consumption) during delays to the LLR (Cohen, 1975; Staddon \& Simmelhag, 1971). In spite of experimenters' rigorous efforts to control the experimental setting, organisms enter experiments 
with rich histories and repertoires containing behavioral tendencies that compete with programmed schedules of reinforcement (Baum, 1981, p. 395). Toward this end, the brief rule "If I wait a little longer, I will get..." may have served as a verbal cue of the contingency, potentially sharing the same function as the images of the reinforcers presented during the delays of Mischel et al.'s studies (e.g., Mischel \& Moore, 1970).

In a similar demonstration involving progressive delays to LLRs, Dixon and Cummings (2001) presented three young children diagnosed with autism the option of having a SSR or a LLR with and without the presence of an intervening task. The specific intervening activity was an identity match-to-sample task in which participants were instructed to pair stimuli on colored index cards with an arrangement of corresponding stimuli. The results were consistent with previous research by Binder, Dixon, and Ghezzi (2000) in that training progressive delays in conjunction with an intervening activity resulted in more self-controlled choices, as defined by a greater number of choices of the larger delayed reward.

Gokey, Wilder, Welch, Collier, and Mathisen (2013) extended the findings of Binder, Dixon, and Ghezzi (2000) and Dixon and Cummings (2001), also with three children diagnosed with autism. Each child was trained in conditions in which a progressive delay to the larger of two reinforcers was presented either in the presence or absence of a concurrent intervening activity. All children demonstrated distinct preference for the LLR in the condition featuring the concurrent intervening activity over the condition that featured only the progressive delay. Once responding reached stability criterion, the authors gradually faded the intervening activity across sessions, holding delay constant at full duration. As the duration of the intervening activity was gradually reduced, participants still withstood the remainder of the delay, with one child engaging in "pretend activities... [like] writing with his finger" (p. 831). These results align with 
those described by Binder et al. (2000) and Dixon and Cummings (2001) by demonstrating the efficacy of intervening activities, but also suggest that once these activities are trained, they can be faded without a preference reversal toward the SSR. Further, the invented finger-writing behavior emitted by one child (in the absence of the programmed intervening activity) provides some support for the generality of intervening behavior to mediate delays. These results fit well within the hypothesis that one can lessen the subjective value of a reward by shifting attention (i.e., behavior) elsewhere. That the participants in Gokey et al. (2013) and Dixon and Cummings (2001) each had an autism diagnosis may have necessitated more explicit training of the delaymediating behaviors, whereas the predominantly typically developing participants in Mischel's studies would often engage in mediating behaviors without specific instructions to do so. A comparison of specific versus vague/general instructions (or tasks) for mediating activities would add to our understanding of the factors that influence DG.

Newquist, Dozier, and Neidert (2012) compared the effects of several different interventions on the self-control of three typically developing preschool children. Specifically, the authors sought to determine the effectiveness of delivering brief rules or providing either a count-down timer or preferred items during a delay on the choice of large delayed edible reinforcer. The brief rules consisted of either experimenter rules (“When you wait, you get...”) or child rules ("When I wait, I get..."), while in the Count-Down Timer and Preferred Item conditions, the experimenter placed the [count-down timer/preferred items] in front of the seated child for the duration of the delay. Results varied from previous research that supported the effectiveness of brief rules and the presence of a count-down timer (e.g., Binder, Dixon, \& Ghezzi, 2000; Hanley, Heal, Tiger, \& Ingvarsson, 2007; Vollmer, Borrero, Lalli, \& Daniel, 1999) - only access to preferred items was demonstrated as an effective means of generating 
self-controlled behavior (i.e., selecting the large delayed edible reinforcer) for the children in this study. One explanation for these findings is the use of a single delay across trials, rather than progressive delays like those used in Binder et al. (2000), Dixon and Cummings (2001), and Gokey et al. (2013). The previous studies demonstrated the effectiveness of incrementally increasing the delays, which may have been a stronger determinant of LLR choices than the presence of intervening activities. Toward this end, the authors posited that the reinforcer potency of the preferred items may have been greater than that of the edible reinforcers presented in this study; this suggests a need for further research on the interaction between the availability of intervening activities and the use of either a single or progressive delay. Nevertheless, these findings provide support for the effectiveness of preferred items in bridging time intervals for young children when reinforcement is delayed.

While the applied behavior analysis examples cited above provide insight into ways to modulate DG, basic studies from the experimental analysis of behavior have contributed to our basic understanding of the impact of delay on suboptimal choice (Mazur, 1987; Rachlin \& Green, 1972). Schweitzer and Sulzer-Azaroff (1988) examined an experimental teaching procedure designed to increase the number of LLR choices in six preschool children who exhibited behavior described by their teachers as "impulsive." The authors built a novel apparatus featuring small drawers from which the children could select either the SSR or the LLR (preferred edibles or stickers). During the teaching procedure, children were initially provided with the choice of both the smaller and larger magnitude reinforcers without delay, with incremental delays subsequently added prior to delivery of the LLR. A post assessment demonstrated that all participants made more LLR choices after being exposed to the incrementally-increasing delays in the teaching procedure. 
Darcheville, Riviere, and Wearden (1992) assessed preference for cartoons under fixedinterval (FI) schedules. Participants $\left(M_{a s e}=6\right.$ years, 1 month $)$ made choices for access to cartoons presented for $20 \mathrm{~s}$ after a $0.5 \mathrm{~s}$ delay (the SSR) or for $40 \mathrm{~s}$ after a $20 \mathrm{~s}$ delay. Participants emitted responses on a console featuring lateral response buttons above which were two illuminated disks that functioned as discriminative stimuli for either immediate (i.e., after $.5 \mathrm{~s}$ ) access to the 20 s reinforcer, or a 20 s delay to the 40 s reinforcer. Participants who made consistently more SSR choices produced higher response rates and shorter post-reinforcement pauses than those who opted for the LLR. The authors offered that "self-control" (i.e., delaying gratification) in a human operant arrangement may be a result of the combinative effects of learning to emit the response that produces reinforcement, and then identifying contexts in which waiting will produce an optimal outcome and when it will not (Darcheville et al., 1992; Sonuga-Barke, Lea, \& Webley, 1989a, b). The authors consider and interpret their findings in light of previous research by van den Broek, Bradshaw, and Szabadi (1987), who found that typically developing adults classified as impulsive (according to psychometric evaluations including the Wechsler Adult Intelligence Scale, the State-Trait Anxiety Scale, and Matching Familiar Figures Test) emitted higher rates of responding under differential reinforcement of low rate (DRL) schedules than the "non-impulsive" adults. The authors found that introducing external (i.e., non-temporal) cues featuring relevant information about the schedule contingencies (e.g., instructions not to emit the operant response until the signal light appeared) established better control over the performance of the "impulsive" group. That participants in Darcheville et al. who favored the SSR also demonstrated higher FI response rates suggests that temporal cues associated with the reinforcement schedules may have been indiscriminable, and that perhaps improved performance would have occurred in the presence of relevant external cues related to the contingencies. The 
role these types of cues play in DG can be seen across the behavioral sciences in the work of Mischel and Moore (1973), Mischel and Baker (1975), Binder et al. (2001), and Dixon and Cummings (2001). These studies demonstrated that elucidating relevant features of the contingency could displace the motivating operation(s) created by the opportunity for immediate gratification.

The studies reported thus far have focused largely on behaviors occurring during the delay to the LLR (e.g., attention to or away from the properties of the reward, brief rules, or access to intervening activities), however, it follows that events in the participants' immediate history may modulate the degree to which waiting the full duration becomes more or less likely. Research on rich-to-lean transitions has shown that potentially problematic behaviors reliably occur when shifting from dense reinforcement schedules to leaner ones, yet to a much lesser degree when lean conditions precede other lean ones (Hagopian, Toole, Long, Bowman, \& Lieving, 2004; Perone \& Courtney, 1992; Williams, 2015; Williams, Saunders, \& Perone, 2011). Both non-human and human research demonstrate FR performance typically results in a postreinforcement pause (PRP) which increases considerably in length when moving from a rich schedule to a leaner one as opposed to lean-to-rich, lean-to-lean, or rich-to-rich (Harzem \& Harzem, 1981; Staddon, 1974; Williams et al., 2013). One may conceptualize recreational consumption of MEM as a densely reinforcing activity in terms of unit price (i.e., the ratio of response effort to reinforcers obtained) that shares many similarities with television viewing. Lillard and Peterson (2011) demonstrated a strong link between fast-paced television programs and a reduced tolerance for delay as well as poorer performance on other executive functioning tasks (e.g., Tower of Hanoi, backward digit span, and "Head, Toes, Knees, and Shoulders”) relative to educational television programs or drawing. It follows that the pace of MEM may also 
provide children with a dense reinforcement schedule that, upon abrupt termination, could result in behavior that may be conceptualized as serving the function of escape from a potentially aversive rich-to-lean transition (Perone \& Courtney, 1992; Williams, 2015; Williams et al., 2011; Retzlaff, Parthum, Pitts, \& Hughes, 2017). Considering this example of negative reinforcement within the framework of DG, the behavior could take the form of suboptimal choosing to terminate the potentially aversive delay while satisfying the motivating operation introduced by the availability of the SSR. Determining the degree to which alternative activities featuring less dense schedules of reinforcement and/or action sequences can be utilized prior to transitions may hold strong implications for parents, teachers, and direct care staff who must aid children with transitioning from highly reinforcing activities to those that are leaner or less preferred.

It appears that now, in a high-speed age where exposure and tolerance to delay may be becoming less and less common due to a proliferation of electronic media devices, there exists a need to reexamine contemporary determinates of self-control in young children. The first aim of the present investigation was to examine any differential effects of exposure to print images, digital images, and an interactive digital game on children's subsequent DG. A second aim was to determine whether a relation exists between operant demand for screen media and time waited in the DG tasks. Based on our review of the literature, we are aware of no direct study of modern screen media (i.e., mobile devices rather than television) consumption on young children's DG, despite evidence that television viewing can negatively affect DG (Lillard \& Peterson, 2011). To our knowledge, this would be the first explicit experimentation of mobile screen media use on DG in children. 


\section{Study 1 Methods}

\section{Participants and Inclusion Criteria}

Three typically developing boys $\left(M_{\text {gse }}=4.47\right.$ years; SD $=3.79$ months $)$ enrolled in a university-run full day preschool participated in the first study. Criteria for recruitment consisted of (1) having no identified developmental or learning disabilities, (2) the ability to follow multistep instructions (e.g., stand up/sit down; high five; press this button) and (3) greater relative preference for a tablet device (i.e., iPad; compared to a book featuring the same stimuli) as indicated by demand assessments (see section below). All guardians received a letter detailing the purpose and procedures of the study (see Appendix 1). Each participant and guardian provided assent and consent, respectively, in order to take part in the study.

\section{Reliability and Procedural fidelity}

Two independent observers collected trial reliability data for the purpose of interobserver agreement (IOA) on at least $30 \%$ of sessions comprising each component of the studies presented here. Both observers were trained on data collection and assessed for accuracy prior to scoring the video recordings. Each independent observer received a task analysis (TA) for video scoring each phase of the study (see Appendices 2-3) prior to the reliability training. In the first training session for each phase of the study, the observer and the experimenter concurrently viewed and scored a randomly selected video session. Accuracy in the DG sessions was defined as recorded wait times differing no more than $\pm 0.5 \mathrm{~s}$. Accuracy of the recorded times was $100 \%$ for both observers prior to scoring the videos. Procedural fidelity assessments occurred across each phase of the study (see Appendices 2-3 for scoring information). 


\section{Operant Demand for e-Book Engagement}

Preference for image themes. After interviewing each participant to obtain a list of preferred cartoon/movie characters, toys, and superheroes, high resolution images of each identified theme were entered into a document and color printed on $21.59 \mathrm{~cm} \times 29.94 \mathrm{~cm}$ pieces of white paper. Each participant completed three five-item multiple stimulus without replacement preference assessments (MSWO; DeLeon \& Iwata, 1996) for each shared image theme (i.e., fives themes identified by all three participants) to be presented on the tablet in ebook format and in the print book. Participants then completed an MSWO to determine a hierarchy of preferred visual stimuli to use in the demand assessment.

Procedure. The experimenter met each participant in the classroom between 10:00 and 11:00 AM and asked the participant if they would like to come to research. Upon gaining assent, the experimenter informed the classroom graduate supervisor that the participant would be attending a research session and signed the participant out on the classroom attendance sheet. The experimenter and participant walked to an adjacent room containing a table and two chairs. A 5-item array of equally-spaced printed images featuring popular children's media themes (including superheroes, Legos ${ }^{\circ}$, dinosaurs, Transformers ${ }^{\circ}$, and characters from the children's television programs [e.g., Paw Patrol ${ }^{\circledR}$; Disney's Cars@]) was presented in a random sequence in a straight line on the table approximately $25 \mathrm{~cm}$ in front of the participant. The experimenter instructed the participant to select an image by saying "pick the one that you like the most." After selecting an image, a white cardboard partition measuring $30.48 \mathrm{~cm}$ x $91 \mathrm{~cm}$ was placed in

- The preschool is run by a research university and each participant had prior experience being accompanied to research sessions for various social and academic skill assessments. Participants were familiar with the contingencies of "going to research," which entailed being escorted out of the preschool classroom by a graduate student for a duration not exceeding $30 \mathrm{~min}$ a day. 
front of the remaining images while the experimenter rotated their positions, moving the leftmost image to the far right and shifting the others so that each image was once again equally spaced. The experimenter noted the position of the image in the array on the datasheet to assess positional biases. After $15 \mathrm{~s}$ of access to the chosen image, the experimenter said "my turn" and removed the image without returning it to the array. The next trial immediately followed and the procedure continued in this manner until either all the images were selected or an image was not chosen within $30 \mathrm{~s}$. All participants made a selection on each of the five trials (accordingly, no images were recorded as "not selected").

Materials and setting. Seated at a table desktop computer within a 1.21 x 2.13 meter room adjacent to a room equipped with a one-way glass window, each participant completed a competing reinforcers assessment (see below) for both a tablet and a print book containing the images identified in the MSWO preference assessments. Because only one of the image themes resulted in a relatively low ranking across the preference assessments, the remaining image themes were arranged in a quasirandom sequence and presented identically on both the tablet and in the print book.

Each modality contained 120 pages of images arranged in approximately equal thematical dispersion (i.e., superheroes, dinosaurs, toys [etc.] were distributed throughout, rather than grouped by theme; see Appendix 4). The tablet was an Apple iPad 2 (16 GB, Model A1395) with a $24.64 \mathrm{~cm}$ (diagonal) screen, housed in a black Griffin AirStrap protective outer case (Model GB02505). Protecting the screen was a red Besdata Ultrathin Magnetic Smart Cover (Model PT 25_26). Images presented on the e-book were in portable document format (PDF) and opened in the $i B o o k s^{\infty}$ application. Following the initial finger swipe (which removed first image), images would immediately enter the tablet screen from right-to-left (RL) or from left-to- 
right (LR), depending on the direction of the participant's finger swipe. Engaging in a single finger-swipe (RL or LR) removed the present image and immediately produced the adjacent image. Images in the print book were bound by concealed steel prong fasteners within a thin, flexible, red plastic cover cut to the identical size specifications of the tablet. In order to control for the amount of image content presented per print and digital page, the images in the print book were printed single-sided, such that the behavior of moving between images (i.e., turning the page/swiping to the next image) would produce the same amount of image content regardless of the modality (printing on both sides of the paper when constructing the print book would result in an image-to-page-turn ratio of 1:2, in that a single turn of the page in the print book would result in two images, whereas a single finger sweep on the tablet would produce one image).

Competing reinforcers assessment. The competing reinforcers assessment (CRA) served as a measure of operant demand for the tablet to quantify the relative reinforcing efficacy of the tablet to the print book. The CRA entailed interaction with a computer program (see Appendix 4) created using JavaScript which featured a text entry box that allowed the experimenter to specify the (a) side of the screen on which each modality was presented, (b) responses required to earn each modality, (c) number of trials in each session, and (d) duration of modality access provided to the participant upon meeting the response requirement. Displayed on one side of the screen was a $7.62 \mathrm{~cm} \times 5.08 \mathrm{~cm}$ image of the tablet while the other side displayed an equally sized image of a print book. Participants emitted the operant responses on two $12.7 \mathrm{~cm}$ diameter blue circular Ablenet * microswitch buttons connected to the desktop computer and placed on the table on the left and right sides of the computer screen. These buttons required $156 \mathrm{~g}$ of force to activate, rendering them appropriate to use with preschool children. Approximately $2.5 \mathrm{~cm}$ beneath the images of the tablet and the print book were small 
$1.27 \mathrm{~cm}$ diameter black circles which represented the total number of button-presses required to access each modality. Upon completing each CRA session, the program generated a CSV file containing the session output. In addition to the session-specific information entered into the entry box prior to initiating the first trial (e.g., session number, tablet fixed ratio [FR] cost, initial side placement of the modality images on the computer screen, and access duration) dependent measures included in the output file consisted of the position of the e-book (left or right side of the screen) across trials, the modality chosen on each trial, the time at which each button-press occurred (time-stamped), and the length of the session.

Procedure. Each participant completed a single 5-trial CRA session per day for six days. Upon reaching the session room, the experimenter instructed the participant to sit in a chair just outside the door and said, "I'm going to press this button, which means we're going to start working." The experimenter then reached into the adjacent booth and initiated the video recording.

Both the participant and the experimenter then entered the session room and the experimenter assisted the participant into a chair at the desk directly in front of the computer and the blue circular buttons. Prior to the first trial of each session, the participant experienced a forced choice procedure in which the tablet and the print book were presented individually (alternating the order across sessions) at the cost emitting an FR1 response using the button on the side of the screen corresponding with the displayed modality. The experimenter told the participant, "This is a picture of a/n [book/iPad]. Press this button [pointing to the button on the side of the presented modality] to make that dot [pointing to the dot] and I'll give you the 
[book/iPad]." After $15 \mathrm{~s}$ of access² to each modality (so as to expose the participant to the content as well as tactile sensations of each), both modalities appeared on the screen available at an FR1. This pre-session assessment served to measure preference for the tablet and print book when the cost to access each modality was equal. Following the 15 -s access period, the tablet and the print book reappeared on the screen with five small black circles beneath the tablet (representing a cost of FR5) and a single small circle beneath the print book (representing a cost of FR1). Instructions were the same as the concurrent FR-1 (i.e., previous) trial, only with the words "that dot" replaced the by words "those dots." Upon meeting the response requirement for the chosen modality, the computer screen turned black and the participant received $15 \mathrm{~s}$ to engage with it freely. Following this access period, the experimenter said, "my turn," removed the item, and once again instructed the participant to choose between the two modalities. Presentation of each modality alternated between the left and right sides of the screen across trials to control for any side biases, with the experimenter reciting the phrase "the pictures and buttons have switched," before repeating the instructions from the previous trial for the remaining four trials. On the next day, the FR requirement (i.e., price) of the tablet increased to FR10, while the book remained available at an FR1. The price of the tablet increased by 10, 30, 50, and 100 responses (to FR20, FR50, FR100, and FR200, respectively) across the remaining four sessions according to a progressive fixed-ratio schedule (Jarmolowicz \& Lattal, 2010). Each participant completed one FR value (i.e., session) per day. While a number of applied human operant studies have employed the use of sequences that ascended in smaller increments (see Trosclair-Laserre, Lerman, Call, Addison, \& Kodak, 2008), more rapidly-increasing schedule values have shown to

2 The $15 \mathrm{~s}$ access duration was chosen in an effort to reduce the likelihood of satiation for each modality. 
minimize the effects of satiation or habituation that may result from repeated exposure (Hodos \& Kalman, 1963; Hoffman et al., 2017). The print book was available at a constant FR 1 across each trial of the six CRA sessions to approximate reinforcer substitutability analyses used in operant demand assays (Hursh, 2014; Reed, Kaplan, \& Becirevic, 2015).

\section{Delay of Gratification}

Preference for edibles. Participants each completed three five-item MSWO preference assessments in order to obtain a hierarchy of preferred edibles to use in the DG procedures based on the seminal Marshmallow Tests conducted by Walter Mischel at Stanford University beginning in the early 1960s (Bandura \& Mischel, 1965; Mischel \& Coates, 1968).

Procedure. The experimenter, wearing latex gloves, placed a single bite-sized edible on five $13.97 \mathrm{~cm}$ diameter white paper plates. Edibles used in the MSWO were chosen based on participants' verbal reports and were purchased in sizes that closely approximated that of the other edibles (e.g., small marshmallows to more closely match the size of the $\mathrm{M} \& \mathrm{Ms}^{\circledR}$ and Skittles $^{\star}$ ). Five varieties of edibles (with each color/flavor represented on the plate of that edible) were randomly sequenced in an array and presented in a straight line approximately $25 \mathrm{~cm}$ in front of the participant. Prior to the first trial, the experimenter asked the participant to identify the name of the edible on each plate. Following accurate identification of each edibles, the experimenter instructed the participant to pick one. After the participant made a selection, the experimenter placed a white cardboard partition in front of the edibles, recording the position and color/flavor of the selected edible on the datasheet and removing the plate from which the single piece of selected edible was taken from the array. The remaining plates were then rotated

${ }^{3}$ One participant (Chet) initially did not correctly identify jelly beans, however, after experimenter correction the participant identified the edible on subsequent sessions. 
in the same manner as the printed images used in the image theme MSWO. After the participant consumed the edible, the experimenter removed the partition and again asked the participant to pick one. The procedure continued until each variety of edible had been selected or the participant did not make a selection within $30 \mathrm{~s}$ of the experimenter's instruction. One participant (Chet) did not select jellybeans on two of the three MSWO sessions.

\section{Baseline Tolerance to Delay (Baseline Condition)}

Materials and setting. Sessions took place once per day between 10:00 and 11:00 AM in a 3.35 meter x 2.13 meter session room with a one-way glass window. The session room contained a table and chair facing a one-way glass mirror. A second chair for the experimenter was located in an alcove of the room farthest away from where the participant was seated. Directly beside the chair was a 1.22 meter x 0.61 meter rectangular storage compartment upon which a 1.14 meter $x 0.91$ meter cork partition board kept the experimenter out of the participants' view ${ }^{4}$ during the delay period of the sessions.

Procedures. After obtaining assent and notifying the graduate classroom supervisor, the experimenter escorted the participant toward the session room. Prior to reaching the session room, the experimenter instructed the participant to sit in a chair just inside the door of the observation booth and said, "I'm going to press this button, which means we're going to start working." View of the adjacent session rooms were above participants' eye level and thus were not visible to the participant. The experimenter then initiated the video recording and escorted the participant to the session room. The experimenter assisted the participant into the chair and recited the following instructions:

${ }^{4}$ Due to institutional Human Subjects Committee policies, participants were prohibited from being alone in session rooms during sessions. 


\begin{abstract}
“Okay, [participant's name], here's a [top preferred edible]. You can eat this
one now, or if you wait, I'll give you two. So, you can eat this one now, or if

you wait until I come back from behind there, I'll give you two. Now, when I

go back there I won't be able to talk, so just remember, you can eat

that one now, or you can wait and I'll give you two."
\end{abstract}

Immediately after reciting the instructions, the experimenter stepped behind the partition and out of the child's view (while the child remained visible to the experimenter), sat down, and initiated a timer on a digital stopwatch for a duration of $10 \mathrm{~min}$. If the participant spoke to the experimenter at any point during the delay the experimenter responded with the phrase "[child's name], I'm working, I can't talk right now." Further attempts by the child to engage the experimenter in conversation were ignored. In the event that a participant needed to use the restroom, the experimenter complied and terminated the session.

Consumption was initially defined as the edible entering the participant's mouth and being swallowed. This definition proved insufficient ${ }^{s}$, as one participant repeatedly licked the edible during the session, resulting in the need for a revised definition of consumption. The present definition of consumption was any part of the edible passing the threshold of the lips into the participant's mouth or any contact with the edible made by the participant's tongue (i.e., licking). In the event that the child consumed the edible prior to the end of the 10 min delay, the

${ }^{5}$ Prior to the revised definition of consumption, one participant received a second preferred edible upon reaching the end of the delay on two sessions, despite having licked/nibbled it several times. Upon revising the definition, each participant was instructed that tasting the edible would count as eating it. 
experimenter continued to monitor the stopwatch until $2 \mathrm{~min}$ had passed in order to reduce the likelihood that the participant would pair consumption of the single edible with termination of the session. No participants consumed the edible late enough in the delay that the 2 mins following consumption extended this phase of the session beyond the 10 min mark. Baseline data collection continued for three more sessions in order to obtain stable responding prior to moving to the next phase of the DG assessment.

\section{Modality Use Prior to Delay of Gratification}

Materials and setting. The purpose of this phase in the study was to determine whether the modality used before the DG task modulated the degree to which participants would wait to receive a larger delayed reward (see Appendix 5). Sessions took place in the same room as the baseline DG assessment. In addition to an e-book and print book modalities - termed e-Book and Book conditions, respectively - a second tablet condition (e-Game) featured a fast-paced, visually dynamic superhero game (Transformers Rescue Bots: Disaster Dash, Budge Studios, 2017). The e-Game condition was a means of assessing whether content type (i.e., pictures versus fast-paced movement and sound) contributed to delay of gratification more (or less-so) than the modality itself. Each participant advanced through the game by finger-swiping the screen in order to collect "power-ups" and avoid obstacles. Two e-game "training" sessions occurred prior to the DG phase of the study to expose participants to the contingencies of the game.

Procedures. Sessions occurred daily between 10:00 and 11:00 AM. On Days 1 through 5 participants completed two sessions in order to make up for any missed sessions due to late arrivals or absences. On these days sessions took place between 4:00 and 5:15 PM. Importantly, conditions alternated such that no one particular modality was presented solely in the morning or 
in the afternoon. Sessions began in the same manner as the Baseline condition, with the exception that upon the child entering the room and sitting on the chair at the table, the experimenter presented the child with one of the three modalities and recited the following:

"Okay [participant's name], here's alan [modality"]. You can [look at; play with] this for a while."

The experimenter then set the timer on the digital stopwatch for a duration of $5 \mathrm{~min}$. At the end of the $5 \mathrm{~min}$, the experimenter approached the child, said "my turn," and removed the modality. The experimenter then recited the rules of the DG task and the remainder of the session proceeded as in the baseline condition. Each participant received each modality condition three times (one modality per session) using a multi-element arrangement for a total of nine sessions. Participants experienced the conditions in a quasirandom? sequence such that no two participants experienced the modalities in the same order across sessions.

\section{Study 1 Results}

\section{Demand for Screen and Print Stimuli}

Figure 1 (left panels) depicts the number of times the fixed-price (FR-1) print book and increasing-price e-book modalities were earned at each FR requirement (i.e., price). The right panels of Figure 1 depict the rate of button-presses when working toward the FR requirement of the e-book. All participants chose the e-book when the price was FR-1 with the exception of Django, who chose the print book in one trial (e-book $=83.3 \%$ of trials). Miles demonstrated the

\footnotetext{
"The experimenter identified the modalities to the child as " $a$ book" in the Book conditions and as "an iPad" in both the e-book and e-game conditions.

On one delay of gratification session, a participant received the Book instead of the scheduled e-book due to an equipment malfunction. Another participant received the e-game across two consecutive sessions.
} 
strongest demand ${ }^{\S}$ for the e-book with allocated responses totaling 1, 500 button-presses, equating to earning access to the tablet 26 times across the six sessions. Django emitted a total of 600 button-presses toward earning the e-book, earning access 17 times across sessions. Chet emitted a total 709 button-presses toward earning the e-book and earned access 13 times, demonstrating the weakest demand for this modality among the participants. While all participants had the opportunity to choose the print book (FR1) at any point during the trial, Chet was the only participant to make this choice after already emitting several responses toward earning the e-book in a trial $\left(F R 20:\right.$ Trial $(T)_{1}=12, T_{2}=6, T_{4}=4, T_{5}=1 ; F R 200: T_{2}=24, T_{4}=$ 28).

Response rate across increasing tablet costs. There were significant differences across participants in the mean button-press responses per second $\left(M_{\mathrm{m}}\right)$ allocated toward earning access to the tablet $F(2,62)=17.61, p<.0001$. Post hoc comparisons using the Bonferroni correction revealed significant differences in $M_{\text {тв }}$ between Miles $(2.41 ;$ SEM $=0.094)$ and Chet $(1.53 ;$ SEM $=0.153), p<.0001$ and between Miles and Django $(1.66 ;$ SEM $=0.091), p<.001$. There was not a statistically significant difference in $M_{\mathrm{m}}$ between Chet and Django, $p>.999$.

\section{Delay of Gratification}

Baseline. Figure 2 (left panels) depicts the time waited for each participant in the Baseline and alternating modalities conditions under the previous definition of consumption (swallowing the edible). The right panels depict the time waited under the revised definition of consumption (any part of the edible reinforcer passing the participant's lips into the mouth or

\footnotetext{
${ }^{8}$ The term "demand" is used in this context to generally capture the construct of motivation to consume particular reinforcers. A textbook definition of demand by Reed and colleagues is, "the extent to which an organism defends consumption of a reinforcer in the face of ... constraints" (2015; pg. 280) -- the participants' performance in the CRA of this study is thereby congruent with the definition of demand.
} 
contact with the participant's tongue) and is reported here. Django waited a total of $24.15 \mathrm{~min}$ $(60 \%)$ in the Baseline condition and engaged in consumption in last three of the four sessions. Chet waited a total of $32.02 \mathrm{~min}(80 \%)$ across the four baseline sessions, engaging in consumption in one session. Miles waited a total of $21.23 \mathrm{~min}(53 \%)$, also engaging in consumption in the last three of the four sessions.

Modality sessions. Participants all demonstrated the longest total wait times (i.e., highest DG) in the Book condition. Two of the three participants (Miles and Chet) had the shortest total wait times in the e-Game condition, while for Django the lowest wait time occurred in the eBook condition. Chet waited for $30 \min (100 \%)$ of the total time across the Book condition sessions, $20.57 \mathrm{~min}(68.6 \%)$ of the total time in the e-Book condition, and 12.14 minutes $(40.5 \%)$ in the e-Game condition. Django waited for $30 \mathrm{~min}(100 \%)$ of the total time in the Book condition, $53 \mathrm{~s}(2.95 \%)$ of the total time in the e-Book condition, and $15.73 \mathrm{~min}(9.1 \%)$ in the eGame condition. Miles waited for $31.41 \mathrm{~s}(1.74 \%)$ of the total time in the Book condition, 16.01 $\mathrm{s}(0.88 \%)$ of the total time in the e-Book condition, and $10.08 \mathrm{~s}(0.56 \%)$ in the e-Game condition.

Interobserver agreement for the DG sessions was defined as any recorded wait times not exceeding $\pm 0.5 \mathrm{~s}$ between independent raters, calculated by dividing the agreements by the sum of the agreements and disagreements, then converting to a percentage. Agreement was initially 93.3\% (with the raters differing on the wait time for Chet on Session 1 of the e-Bookcondition), however, agreement increased to $100 \%$ after Rater 2 reviewed the video of that session. Procedural fidelity was 100\% (notwithstanding delivery of two LLRs for Chet under the previous definition of consumption).

Overall delay of gratification. As a means of examining DG irrespective of presession modality exposure, we aggregated each participant's baseline and individual modality session 
wait times into overall measures of DG. A Kruskal-Wallis test revealed a statistically significant difference in the overall wait times $\chi^{2}(2)=15.78, p=.0004$. A Dunn's multiple comparisons test suggested significant differences in overall wait times between Miles and Chet $(p<.001)$, but not between Miles and Django $(p=.299)$ or Chet and Django $(p=.063)$.

\section{Study 1 Discussion}

In this study we examined preference for an e-book relative to a print book containing identical stimuli, as well as DG after access to either a print book, an e-book containing the same stimuli as the print book, or a fast-paced interactive tablet game. There was a statistically significant difference in overall (i.e., irrespective of modality condition) wait times in the DG phase between Miles (who demonstrated the strongest demand for the e-book in the CRA condition) and the other two participants, Django and Chet. With respect to presession modality use, participants all waited the longest following access to print media relative to the tablet conditions. Important to note, however, is Miles' wait times; while Miles' wait times were also longest in the print book condition, they only differed from the e-Book and e-Game conditions by several seconds. Toward this end, making inferences about the effects of each condition on Miles’ DG warrants caution. One possible explanation for lower wait times in both tablet conditions is that upon termination of one of the tablet conditions, not delaying gratification may have served to lessen the aversive properties of transitioning from a rich schedule of reinforcement to lean one. Indeed, all participants emitted higher response rates in the e-Book conditions than in the Book conditions, which resulted in a much greater number of preferred images viewed in the former.

The decision to retain participants who immediately chose the SSR in the last three trials of Baseline (Django and Miles) was to determine whether any of the experimental conditions 
would increase wait times. This was the case for Django, who demonstrated variability in the experimental conditions despite immediately selecting the SSR in the last three of the four baseline trials. Miles, however, demonstrated persistent preference for the SSR for the duration of the study.

\section{Study 2 Methods}

The purpose of Study 2 was to reproduce the findings of Study 1 with a new group of participants, and to address several limitations of that study. Specifically, we sought to increase the number of sessions, reduce the duration of the delay in the DG task, conduct DG sessions only once per day, and implement an extended Baseline condition following the final modality sessions. The rationale for a return to baseline was to potentially rule out the possibility that variability in responding in the three experimental conditions of Study 1 was merely due to chance.

\section{Participants}

Three boys $\left(M_{\text {вяs }}=3.61\right.$ years; $\mathrm{SD}=4.73$ months $)$ from the same University-run preschool as Study 1 participated in the present study. One of the participants was from an adjacent classroom that served slightly younger children aged 3-4. The other participants were from the same classroom used in Study 1. In order to retain consistency with the media content used in Study 1, only participants who indicated preference for the same image themes and interactive game used in Study 1 were eligible to participate in Study 2.

\section{Operant Demand for e-Book Engagement}

The procedures and setting for the tablet demand assessment were identical to those used in Study 1 . 
Preference for Edibles. Participants each completed three five-item MSWO preference assessments in order to obtain a hierarchy of preferred edibles to use in the DG procedures.

Procedures. After obtaining assent and notifying the classroom supervisor, the experimenter escorted the participant to the same session room (identically furnished) as Study 1, assisted the participant into the chair, and recited the same instructions as in Study 1. These sessions differed from Study 1 only insofar as the duration of the DG period was reduced from $10 \mathrm{~min}$ to $5 \mathrm{~min}$ in an effort to minimize participant fatigue and the reportedly aversive nature of the session lengths used in Study 1 as communicated by those participants.

\section{Study 2 Results}

\section{Demand for Screen and Print Stimuli}

Figure 3 (left panels) depicts the number of times the tablet and print book modalities were earned at each FR requirement (i.e., price). The right panels of Figure 3 depict the rate of button-presses when working toward the FR requirement for the e-book. Herbie selected the tablet on $83 \%$ of the initial FR1 trials and allocated a total of 595 responses toward earning tablet access across the six increasing FR sessions. Buddy selected the tablet on 50\% of the initial FR1 trials with responses allocated toward the tablet totaling 905 . Oscar chose the tablet on $100 \%$ of the FR1 trials, allocating 1095 responses toward earning the tablet across sessions.

Response rate across increasing tablet costs. There were significant differences across participants in $M_{\mathrm{r \textrm {s }}}$ allocated toward earning access to the tablet $\chi^{2}(2)=17.71, p=.0001$. A Dunn's multiple comparisons test reported significant differences in $M_{\mathrm{ps}}$ between Oscar (2.34; $S E M=0.129)$ and Buddy $(1.56 ; S E M=0.114), p<.0001$ and between Oscar and Herbie $(1.88$; $S E M=0.122), p<.05$. There was not a statistically significant difference in $M_{\mathrm{ms}}$ between Herbie and Buddy, $p=.36$. 


\section{Delay of Gratification}

Baseline. Figure 4 depicts the time waited for each participant in the Baseline and alternating modalities conditions. Herbie waited a total of $16.28 \mathrm{~min}(81 \%)$ across his four baseline sessions, engaging in consumption in only the first session. Buddy waited a total of $15.06 \mathrm{~min}(60 \%)$ across the baseline sessions and consumed the reinforcer in the first two of his five sessions. Oscar waited a total of $38.26 \mathrm{~s}$ (2\%), also engaging in consumption in each of his seven sessions.

Modality sessions. As in Study 1, all participants demonstrated the longest total wait times in the Book condition and the shortest total wait times in the e-Game conditions. Herbie waited for $20 \mathrm{~min}(100 \%)$ of the total time in the Book condition, $24.92 \mathrm{~min}(99.6 \%)$ of the total time across the e-Book conditions, and $10.8 \mathrm{~s}$ (43\%) across the e-Game conditions. Buddy waited for $20 \mathrm{~min}(100 \%)$ of the total time in the Book condition, $18.4 \mathrm{~min}(73.5 \%)$ of the total time in the e-Book condition, and $12.1 \mathrm{~min}(48.2 \%)$ in the e-Game condition. Oscar waited for $38.3 \mathrm{~s}(1.8 \%)$ of the total time in the Book condition, $23.74 \mathrm{~s}(1.5 \%)$ of the total time in the eBook condition, and $17.86 \mathrm{~s} \mathrm{(1.2 \% )} \mathrm{in} \mathrm{the} \mathrm{e-Game} \mathrm{condition.}$

Interobserver agreement was defined and calculated in accordance with the methods of Study 1. Agreement between raters on time waited in Study 2 was 100\%. Procedural fidelity scores for Studies 1 and 2 were calculated as the quotient of experimenter steps performed correctly over the total steps possible (converted to a percentage). Steps on the procedural fidelity checklist were performed with $100 \%$ accuracy across the CRA and DG sessions sessions.

Overall delay of gratification. We aggregated wait times for the Baseline and individual modality sessions for each participant to quantify DG notwithstanding presession exposure to the book and tablet modalities. A Kruskal-Wallis test revealed a statistically significant difference in 
overall wait times in the DG sessions $\chi^{2}(2)=48.4, p<.0001$. A Dunn's multiple comparisons test suggested significant differences in overall wait times between Herbie and Oscar $(p<.0001)$ as well as Buddy and Oscar $(p<.0001)$, but not between Herbie and Buddy $(p>.999)$.

e-Book Demand and Delay of Gratification. We performed a series of correlations to describe the relationship between the proportion of the total time waited across the DG sessions in Studies 1 and 2 and three different indices of e-book demand in the CRA sessions: the total number of times participants earned the tablet across sessions, response rate across FR requirements, and the proportion of total possible (tablet) responses allocated to earning the tablet. We found no relation between e-book demand and the proportion of total time waited in the Baseline or e-Book conditions (all $p \mathrm{~s}<.05$ ). There was a statistically significant correlation for the Book condition (e-book earned across sessions: $r=-.91, p=.01$; rate of responding: $r=-$ $.95, p=.004$; and proportion of total responses allocated to earning the e-book: $r=-.87, p=.02$ ). We found statistically significant correlations between time waited in the e-Game condition and the number of times participants earned the e-book $(r=-.84, p=.04)$ and rate of responding while meeting the FR requirements of the e-book $(r=-.71, p=.03)$. After aggregating the proportion of total time waited across each DG condition (i.e., irrespective of pre-delay modality access), the number of times participants earned the e-book in the CRA was the only measure significantly associated with overall wait times, $r=-.83, p=.04$. Taken together, these results suggest strong associations between preference for the e-book and reduced tolerance to delay.

\section{Study 2 Discussion}

In Study 2 we successfully reproduced and extended the main findings of Study 1 . The relation between preference/demand for the e-book was inversely related to the proportion of total time waited across the DG phase of the study. A second finding in line with the results of 
Study 1 was the role of presession modality use and DG. Specifically, we observed the shortest wait times from participants after access to the e-Game and e-Book conditions (relative to the Book condition). Study 2 benefitted from a greater number of sessions and a return to Baseline, both of which suggest the variability in responding across the different conditions was not merely due to chance. Worth noting is the atypical use of multi-element research designs and reversals to baseline conditions; multi-element designs provide a means of demonstrating experimental control through observed separation of the data paths associated with each condition, typically rendering a return to baseline conditions unnecessary. Rationale for the return to Baseline in the present study was to provide additional visual evidence that variability observed in the experimental conditions was not a function of extra-experimental variables.

\section{General Discussion}

The present studies experimentally assessed young children's relative demand for digital and print media and the degree to which these modalities interact with DG. These investigations provide two important findings; first, we discovered a systematic relation between excessive demand for an e-book (relative to a print book containing identical stimuli) and shorter wait times across DG sessions. Second, for participants demonstrating the ability to tolerate delays, we found presession access to either an interactive tablet game or an e-book containing preferred stimuli resulted in lower wait times than when exposed to a print book during the pre-DG access period. These findings offer several promising avenues with which both application and basic research may benefit. In terms of young children's demand for digital media, our results provide evidence that access to these devices should serve as highly potent reinforcers. That participants in both studies of the present investigation emitted, on several trials, 200 hundred operant responses in exchange for a $15 \mathrm{~s}$ e-book access period speaks to the power of electronic media. 
Utilizing iPads, tablets, and smartphone apps contingent on desired behavior (even for brief access periods) may increase (or maintain) these desired behaviors. Further, the data from studies 1 and 2 provide evidence that print media becomes a relatively more reinforcing commodity when the costs (i.e., work/effort) become too high. As such, parents, caregivers, and educators may benefit by structuring either a closed economy (see Imam, 1993), where access to digital media is contingent upon desired behavior during important intervals (e.g., lessons, clean-up, or planned prosocial activities), or a token economy (see Hackenberg, 2018), wherein periods of MEM access are earned and redeemed by way of a point system. The high demand for MEM demonstrated by all participants in the present investigation suggests that providing access to this modality contingent upon points accrued in a token economy could maintain high rates of desired behavior both in the home and in educational settings.

Research suggests that behavioral processes underlying delay discounting and DG are not identical (Paglieri, 2013; Rachlin, 2000; cf. Reynolds \& Shiffbauer, 2005). While theories of DG frequently implicate mechanisms such as "Hot" (i.e., impulsive) and "Cool" (i.e., selfcontrolled/regulatory) cognitive systems, much delay discounting research emphasizes stimulus control and overt behavior (Rachlin, 2000; Reynolds \& Shiffbauer, 2005, p. 443). Further, in DG, participants may choose to "defect" to the SSR at any point, whereas choice in delay discounting commits the participant to the choice once made (Paglieri, 2013). Despite these theoretical differences, delay discounting and DG share several key commonalities. For example, we can say that the time to delivery of the LLR in a DG trial may result in a participant discounting the value of that LLR as the relative subjective value of the SSR increases with each second of the delay. Because participants in a typical DG trial are naïve to when the experimenter will return, choosing the SSR several minutes into the trial may be a function of the 
reduction in value of the LLR due to participant perceptions that the delay to the LLR is increasing (Reynolds \& Shiffbauer, 2005). Here, the increase in relative subjective value of the SSR as a function of the temporal distance to the LLR align the processes of DG and delay discounting. Recent research suggests that dependence on technology is associated with steeper delay discounting (e.g., Ferraro \& Weatherly, 2016; Reed, Becirevic, Atchley, Kaplan, \& Liese, 2016). That children with accentuated demand for digital media also exhibited the most pronounced sensitivity to delay is a contribution that may bring us closer to bridging the gap in what we know about delay discounting in young children and adults.

The relation between intervening activities and choosing the LLR (or waiting longer) appears robust and there is evidence to suggest that explicitly trained delay-mediating behaviors can be faded while maintaining tolerance to delays (Gokey et al., 2013). It is unclear, however, as to whether delays mediated by tablets or smart phones may be faded while retaining some tolerance to the previously mediated delay. It is possible that the schedule of reinforcement that accompanies the use of these devices may divert children's attentional mechanisms away from any stimuli signaling that a delay is in place such that no tolerance to delay is learned. While the intervening activities reported in much of the previous research helped to bridge the delay (e.g., Binder, Dixon, \& Ghezzi, 2000; Dixon \& Cummings, 2001), none involved a unit price so low as to be comparable to a finger tap/swipe that produces novel images or results in a character jumping or flying within a digital environment that is already densely reinforcing in terms of visual and auditory stimuli.

Previous research has demonstrated links between age and sensitivity to delay (Garon, Johnson, \& Steeves, 2011; Ito, Saeki, \& Sorama, 2009). It is possible that time intervals may be too ambiguous for young children given their lack of experience with units of time or a history of 
knowing exactly when an experimenter will return with a second (or more preferred) reinforcer. That several studies have produced findings that align with this hypothesis underscore the importance of presenting young children with activities that operate on various schedules of reinforcement, so as to build discrimination between differing amounts of output (responses or time-waited). One can make the case that few, if any, commodities can provide reinforcement schedules as dense (defined by unit price) as those delivered by mobile electronic media. It remains unknown whether tolerance to delay can be taught by pairing access to a tablet or a smart phone with delays to a qualitatively different reinforcer (e.g., preferred edibles).

\section{Translational Implications}

Rich-to-lean transitions. The findings reported in the DG phases of the present studies may be interpreted within the conceptual framework of rich-to-lean transitions (e.g., Williams, 2015) on several grounds. Participants in Experiment 1 demonstrated the longest wait times in the modified Marshmallow Test (Mischel, 1966) following access to print media (presented as a print book) relative to the digital media options. Thus, the transition from a relatively lean schedule of reinforcement (such as that associated with the rate of image "consumption" when viewing print book) into a context involving demands or effort may result in less of a reinforcement contrast than after consuming media presented according to the considerably denser schedule associated with the tablet. That the stimuli contained in both the Book and the eBook conditions were identical emphasizes the notion that the differences in subsequent DG wait times must exist, in some part, due to the manner (e.g., rate, unit price) by which the media is consumed. Indeed, the rate at which participants viewed print images was a fraction of the rate 
with which they viewed images on the tablet ${ }^{\circ}$. Such quantification of the respective schedules of reinforcement provides insight as to the type of transition the participant may be experiencing upon cessation of the modality access period and initiation of the DG task. Conceptually, a child who experiences termination of a rich schedule of reinforcement may be more inclined to make a short-sighted choice if it ameliorates the potentially aversive aspects of the rich-to-lean transition. It follows that the disparity between schedule density and the subsequent DG trial would be the greatest for the e-Book and e-Game conditions. That the longest wait times across all participants in both Studies 1 and 2 were in the Book conditions provides support for this hypothesis. A cursory glance at the differences in image viewing between the Book and e-Book conditions reveals that the density of reinforcement (as defined by images encountered per the 5min access period) as considerably greater when using a tablet relative to the print book. Had participant wait times decreased from baseline across all three conditions, it would be reasonable to posit a rich-to-lean transition irrespective of the mode and pace of pre-DG engagement.

Just as longer FR post-reinforcement pauses observed in rich-to-lean transitions are disruptive to operant responding (Perone \& Courtney, 1992; Williams, Saunders, \& Perone, 2011), escape from the rich-to-lean transition theorized in the present investigations was a disruption to making the optimal choice (i.e., waiting for the LLR). Viewing children's interaction with screen media as operant behavior under a rich schedule of reinforcement may shed light on the sometimes-challenging behaviors that may occur when transitioning from screen to lean.

\footnotetext{
${ }^{9}$ The number of images seen (i.e., pages turned) during the 5-min access period was approximately $35-40$ in the Book condition and approximately $200-250$ in the e-Book condition across participants.
} 
Behavioral momentum theory. Nevin, Mandell, and Atak (1983) offered that behavior carries with it momentum, likening it to the physical momentum described by Newton's law of physical motion. Here, resistance to change (under changing environmental conditions) is analogous to mass, while velocity is analogous to response rate (Banda, Neisworth, \& Lee, 2003; Nevin \& Grace, 2000). Within any response class are responses that have a high probability of occurring and those with a low probability of occurring. Applying this concept to a practical example, a therapist may wish to increase a client's compliance with requests; by presenting a series of requests with which an individual exhibits a high probability of complying builds momentum; as compliance with these requests is reinforced and the response rate within the response class increases, carrying through to requests that have a lower probability of occurring (Banda et al., 2003). Conceptually, activities that present a dense schedule of reinforcement should be followed by an increased likelihood of behaviors that maintain the contiguity of that schedule. Making an SSR choice should then be more probable immediately following dense schedules like those found in the e-Book and e-Game conditions than in the Book condition, given the greater momentum (i.e., response rate due to reinforcement) built during the access periods and stark environmental contrast upon termination and initiation of the delay to gratification. Compare, for example, the rate of page turns in the Book condition with the rate of finger-swipes in the e-Book conditions. That the rate of finger-swipes exceeded that of page turns by approximately $85 \%$ within a 5-min span suggests that transitioning from the former should encounter greater resistance when immediately shifting to a DG task. Further, upon terminating a rich schedule, the participant may demonstrate a type of response variability consisting of behaviors that have previously demonstrated close correspondence between response and reinforcement (e.g., selecting and tasting a preferred edible). While sitting and 
waiting for a larger reward may produce more optimal outcomes, preschool-age participants arguably should have a more extensive and reliable history of seeing, reaching, and tasting, than seeing, waiting and then receiving something greater. Toward this end, the likelihood of engaging in behaviors that approximate the close correspondence between response and reinforcement should be greater following termination of a dense schedule than after a relatively lean one.

Reinforcer pathologies. The reinforcer pathology model refers to the combinative effects of assiduously high valuation of a reinforcer and/or a disproportionate preference for the immediate consumption of, or access to, a commodity, notwithstanding suboptimal long-term outcomes (Bickel, Johnson, Koffarnus, MacKillop, \& Murphy, 2014). The findings of the present investigation support this behavioral model and integrate well with both the initial and longitudinal findings of Walter Mischel. Specifically, participants who demonstrated the greatest demand for the more densely reinforcing commodity also exhibited a greater preference for more immediate outcomes at the expense of the delayed, more optimal reinforcer. The relationship between persistent demand for a densely-reinforcing commodity and preference for more immediate outcomes in the present investigation may serve as an intermediate screening tool for identifying childhood behavioral correlates of maladaptive behaviors that may present in adolescence and adulthood. Methods for repairing this behavioral pattern, such as working memory training (Bickel, Yi, Landes, Hill, \& Baxter, 2011) and episodic future thinking (Peters \& Büchel, 2010) may hold utility in these younger populations. Indeed, Moore, Mischel, and Zeiss (1976) found that tasking young participants with covertly verbalizing abstract properties (i.e., images) of the delayed larger (or more preferred reward) resulted in a reduction in suboptimal, more-immediate choices. 
Referring to Mischel and Baker (1975) and Mischel et al. (1989), the rate of reinforcement in e-Book and e-Game conditions could be conceptualized as eliciting an action sequence following removal of these commodities. The rate of finger-swipes and concurrent digital image consumption in the e-Book condition as well as the ratio of finger swipes to dynamic visual and auditory stimuli in the e-Game conditions was well above that in the Book conditions. As such, the relatively lower rate of interaction with the print book modality may have had a suppressive effect on the action sequences elicited by the e-Bookand e-Game conditions, resulting in less competition between acting on the SSR and delaying gratification. The relationship between response rate in the tablet demand assessment and DG align with the findings of Darcheville et al. (1992), in that there was a negative correlation between the rate of operant responding and "self-control" (i.e., time-waited, in the case of the present investigation).

The relation between response rate and in the demand for digital media sessions and DG may hold promise for educators with respect to selecting the most effective medium/modality to present material. It follows that children for whom the tablet was preferred may experience greater gains when educational material and exercises are presented in this format, as opposed to print. That the digital modality maintained responding at an FR200 when the print book was held constant across sessions at an FR 1 speaks to this assertion. With the overwhelming digital competition faced by print modalities, it seems prudent to account for individual preferences when presenting educational material. However, when considering leisure activities, preference for print media increased across all participants when the cost of accessing digital media became too high. Toward this end, access to digital media contingent on maintained rates (or durations) of desired behavior may well serve a potent reinforcer that young individuals will work hard to obtain. 


\section{Limitations}

Despite the promise of the present investigations, several limitations temper interpretation of the findings. Beginning with the behavioral economic concept of open and closed economies (see review by Imam, 1993), we were unable to control for participants' access to screen media or preferred edibles beyond the experimental setting. Outside of caregiver reports, we obtained no measure of the frequency and duration of screen media access when participants were at home. Toward this end, we had no means of inferring to what extent the tablet may have functioned as a conditioned reinforcer, regardless of the content. It is possible that mobile electronic media may have been paired with positively reinforcing stimuli in the past, or with periods of minimal demands when delivered as a means of occupying the participant while caregivers allocated attention elsewhere. Future research should evaluate methods to control for reinforcing aspects of the modality as well as stimuli signaling the response requirement. Indeed, Findley and Brady (1965) demonstrated sustained performance at FR-4,000 in a chimpanzee in the presence of discriminative stimuli correlated with access to food (pp. 128129). With respect to the dots representing the FR requirement in the CRA, disrupting the pairing between the dots and delivery of the selected reinforcer (i.e., the book or the e-book) may provide evidence as to whether the dots themselves functioned as conditioned reinforcers. Returning to the concept of economy type, participants did not have access to tablets in their respective classrooms, yet the classes would present potentially-substitutable child-themed television programs or segments of popular children's movies at points throughout the day. As such, our ability to infer that variance in demand for, or DG following, MEM was solely accounted for by the experimental preparation is limited in that regard. 
With respect to the CRA sessions, FR200 was the highest cost presented to participants, yet we did not reach an FR value that suppressed responding completely across all participants. Future investigations should examine higher FR values to provide a clearer picture of the degree to which participants will defend access to digital media when faced with increasing response requirements.

Another factor that limits interpretation of the present findings is the waiting period imposed following selection of the SSR in the DG sessions. While participants choosing the SSR were required to wait for 2 minutes (following consumption of the edible) before returning to their respective classrooms, this delay resulted in termination of the session sooner than it would had the participant waited the full duration for the LLR. It may be the case that the slight reduction in session time made selecting the SSR a more attractive choice. Further, all participants had access to various preferred edible reinforcers at points throughout the day in the classroom. It is plausible that the notion of a potentially substitutable edible reinforcer available outside the experimental setting may have served as an abolishing operation for DG during some experimental sessions. Furthermore, because participants in the experimental setting could only access the top-preferred edible identified in MSWO assessments, there existed the risk of satiation over the course of the delay of gratification phase. This concern, however, was assuaged due to no detectable effects of satiation in participant wait times. Another point certainly worthy of mention regards the duration of access to the digital media prior to the DG task. Participants in both studies experienced a 5 min modality access period prior to each DG session, which may not be comparable to periods of access when under parental care. In light of the differences in DG wait times across the three modality conditions, the question remains as to the effect of longer access periods. A natural course for future research would be to present print 
and digital modalities across lengthier intervals. A simple experimental manipulation of this sort may bring to bear a clearer picture of the behavioral manifestation of technology-mediated richto-lean transitions in preschool children.

\section{Conclusion}

The relation between overall demand for digital media and DG warrants, perhaps, a cautionary word to anyone caring for young children. Participants who demonstrated the greatest demand for digital media (as defined by higher response rates and number of responses allocated toward earning the tablet, as well as a higher proportion of trials in which the tablet was earned) also demonstrated the lowest overall wait times in the DG procedures. This finding presents a clear relation between preference for digital media and "self-control," defined here as forgoing a small immediate reinforcer in favor of a larger delayed reinforcer. By demonstrating this relation across two different groups of children, we can justify a call for further research on the correlates between exposure to, and high preference for, digital media and behaviors associated with greater long-term outcomes. As caregivers and educators work to accommodate generations for whom tolerance to delay has been mediated by access to densely reinforcing screen technologies, there exists a need to assess and train behaviors related to self-control. In so doing, these young individuals may be better-equipped to forgo the path of least resistance accompanying smallersooner choices. 


\section{References}

Achmadi, D., Kagohara, D. M., van, d. M., O'Reilly, M. F., Lancioni, G. E., Sutherland, D., ... Sigafoos, J. (2012). Teaching advanced operation of an ipod-based speechgenerating device to two students with autism spectrum disorders. Research in Autism Spectrum Disorders, 6(4), 1258-1264. doi: 10.1016/j.rasd.2012.05.005

Anderson, S. E., Economos, C. D., \& Must, A. (2008). Active play and screen time in US children aged 4 to 11 years in relation to sociodemographic and weight status characteristics: a nationally representative cross-sectional analysis. BMC public health, 8(1), 366-379. doi: 10.1186/1471-2458-8-366

Banda, D. R., Neisworth, J. T., \& Lee, D. L. (2003). High-probability request sequences and young children: Enhancing compliance. Child \& Family Behavior Therapy, 25(2), 17-29. doi: 10.1300/J019v25n02_02

Bandura, A., \& Mischel, W. (1965). Modifications of self-imposed delay of reward through exposure to live and symbolic models. Journal of Personality and Social Psychology, 2(5), 698-705. doi: 10.1037/h0022655

Baum, W. M. (1981). Optimization and the matching law as accounts of instrumental behavior. Journal of the Experimental Analysis of Behavior, 36(3), 387-403. doi: $10.1901 /$ jeab.1981.36-387

Bickel, W. K., Johnson, M. W., Koffarnus, M. N., MacKillop, J., \& Murphy, J. G. (2014). The behavioral economics of substance use disorders: Reinforcement pathologies and their repair. Annual Review of Clinical Psychology, 10, 641-677. doi:10.1146/annurev-clinpsy$032813-153724$ 
Binder, L. M., Dixon, M. R., \& Ghezzi, P. M. (2000). A procedure to teach self-control to children with attention deficit hyperactivity disorder. Journal of Applied Behavior Analysis, 33(2), 233-237. doi: 10.1901/jaba.2000.33-233

Bleakley, A., Jordan, A. B., \& Hennessy, M. (2013). The relationship between parents' and children's television viewing. Pediatrics, 132(2), e364-e371. doi: 10.1542/peds.20123415

Burke, A., \& Marsh, J. (eds) (2013). Children's Virtual Play Worlds: Culture, Learning, and Participation. New York: Peter Lang

Cadoret, G., Bigras, N., Lemay, L., Lehrer, J., \& Lemire, J. (2018). Relationship between screentime and motor proficiency in children: A longitudinal study. Early Child Development and Care, 188(2), 231-239. doi: 10.1080/03004430.2016.1211123

Carey, A. C., Friedman, M. G., \& Bryen, D. N. (2005). Use of electronic technologies by people with intellectual disabilities. Mental Retardation, 43(5), 322-333. Retrieved from https://search-proquest-com.www2.lib.ku.edu/docview/620966210?accountid=14556

Carson, V., Spence, J. C., Cutumisu, N., \& Cargill, L. (2010). Association between neighborhood socioeconomic status and screen time among pre-school children: A crosssectional study. BMC Public Health, 10(1), 367-375. doi: 10.1186/1471-2458-10-367

Charlop-Christy, M., Le, L., \& Freeman, K. A. (2000). A comparison of video modeling with in vivo modeling for teaching children with autism. Journal of Autism and Developmental Disorders, 30(6), 537-552. doi: 10.1023/A:1005635326276

Cohen, I. L. (1975). The reinforcement value of schedule-induced drinking. Journal of the Experimental Analysis of Behavior, 23(1), 37-44. doi: 10.1901/jeab.1975.23-37 
Darcheville, J. C., Rivière, V., \& Wearden, J. H. (1992). Fixed-interval performance and selfcontrol in children. Journal of the Experimental Analysis of Behavior, 57(2), 187-199. doi: $10.1901 /$ jeab.1992.57-187

DeLeon, I. G., \& Iwata, B. A. (1996). Evaluation of a multiple-stimulus presentation format for assessing reinforcer preferences. Journal of Applied Behavior Analysis, 29(4), 519-533. doi: 10.1901/jaba.1996.29-519

de Moraes Ferrari, G.L., Araujo, T. L., Oliveira, L., Matsudo, V., Mire, E., Barreira, T. V., .. . Katzmarzyk, P. T. (2015). Association between television viewing and physical activity in 10-year-old Brazilian children. Journal of Physical Activity \& Health, 12(10), 14011408. doi: 10.1123/jpah.2014-0406

Dixon, M. R., \& Cummings, A. (2001). Self-control in children with autism: Response allocation during delays to reinforcement. Journal of Applied Behavior Analysis, 34(4), 491-495. doi: 10.1901/jaba.2001.34-491

Duch, H., Fisher, E. M., Ensari, I., \& Harrington, A. (2013). Screen time use in children under 3 years old: A systematic review of correlates. The International Journal of Behavioral Nutrition and Physical Activity, 10, 10. doi: 10.1186/1479-5868-10-102

Dutra, G. F., Kaufmann, C. C., Pretto, A. D. B., \& Albernaz, E. P. (2016). Sedentary lifestyle and poor eating habits in childhood: a cohort study. Ciencia \& Saude Coletiva, 21(4), 1051-1059. doi: 10.1590/1413-81232015214.08032015

Ferraro, F. R., \& Weatherly, J. N. (2016). Texting dependence, iPod dependence, and delay discounting. The American Journal of Psychology, 129(2), 161-168. doi: 10.5406/amerjpsyc.129.2.0161 
Findley, J. D., \& Brady, J. V. (1965). Facilitation of large ratio performance by use of conditioned reinforcement. Journal of the Experimental Analysis of Behavior, 8(2), 125129. doi: 10.1901/jeab.1965.8-125

Garon, N., Johnson, B., \& Steeves, A. (2011). Sharing with others and delaying for the future in preschoolers. Cognitive Development, 26(4), 383-396. doi: 10.1016/j.cogdev.2011.09.007

Gokey, K. M., Wilder, D. A., Welch, T., Collier, A., \& Mathisen, D. (2013). Fading a concurrent activity during self- control training for children with autism. Journal of Applied Behavior Analysis, 46(4), 827-831. doi: 10.1002/jaba.77

Hackenberg, T. D. (2018). Token reinforcement: Translational research and application. Journal of Applied Behavior Analysis. Advance online publication. doi: 10.1002/jaba.439

Hagopian, L. P., Toole, L. M., Long, E. S., Bowman, L. G., \& Lieving, G. A. (2004). A comparison of dense-to-lean arid fixed lean schedules of alternative reinforcement and extinction. Journal of Applied Behavior Analysis, 37(3), 323-337.

doi: 10.1901/jaba.2004.37-323

Hanley, G. P., Heal, N. A., Tiger, J. H., \& Ingvarsson, E. T. (2007). Evaluation of a classwide teaching program for developing preschool life skills. Journal of Applied Behavior Analysis, 40(2), 277-300. doi: 10.1901/jaba.2007.57-06

Hart, B., \& Risley, T. R. (1995). Meaningful differences in the everyday experience of young American children Paul H Brookes Publishing, Baltimore, MD. Retrieved from https://search-proquest-com.www2.lib.ku.edu/docview/618768959?accountid=14556

Hodos, W., \& Kalman, G. (1963). Effects of increment size and reinforcer volume on progressive ratio performance. Journal of the Experimental Analysis of Behavior, 6(3), 387-392. doi: 10.1901/jeab.1963.6-387 
Hoffmann, A. N., Samaha, A. L., Bloom, S. E., \& Boyle, M. A. (2017). Preference and reinforcer efficacy of high- and low- tech items: A comparison of item type and duration of access. Journal of Applied Behavior Analysis, 50(2), 222-237. doi: 10.1002/jaba.383

Hursh, S. R. (2014). Behavioral economics and the analysis of consumption and choice. In F. K. McSweeney, \& E. S. Murphy (Eds.), The Wiley Blackwell Handbook of Operant and Classical Conditioning (pp. 275-305, Chapter xxii, 738 Pages) Wiley-Blackwell. doi: $10.1002 / 9781118468135 . \operatorname{ch} 12$

Imam, A. A. (1993). Response-reinforcer independence and the economic continuum: A preliminary analysis. Journal of the Experimental Analysis of Behavior, 59(1), 231-243. doi: 10.1901/jeab.1993.59-231

Ito, M., Saeki, D. \& Sorama, M. (2009). Local and overall reinforcement density as a determiner of self-control in preschool children: A preliminary analysis. Studies in the Humanities, 60, 94-109. http://dlisv03.media.osaka-cu.ac.jp/infolib/usercontents/kiyo/DBd0600005

Jameson, J. M., Thompson, V., Manuele, G., Smith, D., Egan, H., \& Moore, T. (2012). Using an iTouch to teach core curriculum words and definitions: Efficacy and social validity. Journal of Special Education Technology, 27(3), 41-54. doi:10.1177/016264341202700304

Jarmolowicz, D. P., \& Lattal, K. A. (2010). On distinguishing progressively increasing response requirements for reinforcement. The Behavior Analyst, 33(1), 119-125.

doi: 10.1007/BF03392207 
Kagohara, D. M., van, d. M., Ramdoss, S., O'Reilly, M. F., Lancioni, G. E., Davis, T. N., .. . Sigafoos, J. (2013). Using iPods ${ }^{\circledR}$ and iPads ${ }^{\circledR}$ in teaching programs for individuals with developmental disabilities: A systematic review. Research in Developmental Disabilities, 34(1), 147-156. doi: 10.1016/j.ridd.2012.07.027

Kirkorian, H. L., Pempek, T. A., Murphy, L. A., Schmidt, M. E., \& Anderson, D. R. (2009). The impact of background television on parent-child interaction. Child Development, 80(5), 1350-1359. doi: 10.1111/cdev.2009.80.issue-510.1111/j.1467-8624.2009.01337.x

Kondo, Y., Tanabe, T., Kobayashi-Miura, M., Amano, H., Yamaguchi, N., Kamura, M., \& Fujita, Y. (2012). Association between feeling upon awakening and use of information technology devices in Japanese children. Journal of epidemiology, 22(1), 12-20. doi: 10.2188/jea.JE20110019

Lauricella, A. R., Wartella, E., \& Rideout, V. J. (2015). Young children's screen time: The complex role of parent and child factors. Journal of Applied Developmental Psychology, 36, 11-17. doi: 10.1016/j.appdev.2014.12.

LeBlanc, L. A., Coates, A. M., Daneshvar, S., Charlop-Christy, M., Morris, C., \& Lancaster, B. M. (2003). Using video modeling and reinforcement to teach perspective-taking skills to children with autism. Journal of Applied Behavior Analysis, 36(2), 253-257. doi: 10.1901/jaba.2003.36-253

Lemmon, K., \& Moore, C. (2007). The development of prudence in the face of varying future rewards. Developmental Science, 10(4), 502-511. doi: 10.1111/j.1467-7687.2007.00603.x Lillard, A. S., \& Peterson, J. (2011). The immediate impact of different types of television on young children's executive function. Pediatrics, 128(4), 644-649. doi: $10.1542 /$ peds.2010-1919 
Lin, L., Cherng, R., Chen, Y., Chen, Y., \& Yang, H. (2015). Effects of television exposure on developmental skills among young children. Infant Behavior \& Development, 38, 20-26. doi: 10.1016/j.infbeh.2014.12.005

Logue, A. W. (1988). Research on self-control: An integrating framework. Behavioral and Brain Sciences, 11(4), 665-709. doi: 10.1017/S0140525X00053978

Maich, K., \& Hall, C. (2016). Implementing iPads in the inclusive classroom setting. Intervention in School and Clinic, 51(3), 145-150. doi: 10.1177/1053451215585793

Mazur, J. E. (1987). An adjusting procedure for studying delayed reinforcement. In M. L. Commons, J. E. Mazur, J. A. Nevin \& H. Rachlin (Eds.), The effect of delay and of intervening events on reinforcement value; the effect of delay and of intervening events on reinforcement value (pp. 55-73, Chapter xvii, 344 Pages) Lawrence Erlbaum Associates, Inc, Hillsdale, NJ. Retrieved from https://search-proquestcom.www2.lib.ku.edu/docview/617226485?accountid=14556

McQueen, A., Cress, C., \& Tothy, A. (2012). Using a tablet computer during pediatric procedures: a case series and review of the "apps". Pediatric Emergency Care, 28(7), 712-714. doi: 10.1097/PEC.0b013e31825d24eb

Mineo, B. A., Ziegler, W., Gill, S., \& Salkin, D. (2009). Engagement with electronic screen media among students with autism spectrum disorders. Journal of Autism and Developmental Disorders, 39(1), 172-187. doi: 10.1007/s10803-008-0616-0

Mischel, W. (2014). The marshmallow test: Understanding self-control and how to master it. New York: Little, Brown, \& Company. 
Mischel, W. (1966). Theory and research on the antecedents of self-imposed delay of reward. In B. A. Maher (Ed.), Progress in Experimental Personality Research. New York: Academic Press.

Mischel, W., \& Baker, N. (1975). Cognitive appraisals and transformations in delay behavior. Journal of Personality and Social Psychology, 31(2), 254-261. doi: 10.1037/h0076272

Mischel, W., Coates, B., \& Raskoff, A. (1968). Effects of success and failure on selfgratification. Journal of Personality and Social Psychology, 10(4), 381-390. doi: $10.1037 / \mathrm{h} 0026800$

Mischel, W., \& Ebbesen, E. B. (1970). Attention in delay of gratification. Journal of Personality and Social Psychology, 16(2), 329-337. doi: 10.1037/h0029815

Mischel, W., Ebbesen, E. B., \& Raskoff Zeiss, A. (1972). Cognitive and attentional mechanisms in delay of gratification. Journal of Personality and Social Psychology, 21(2), 204-218. doi: $10.1037 / \mathrm{h} 0032198$

Mischel, W., \& Moore, B. (1973). Effects of attention to symbolically presented rewards on selfcontrol. Journal of Personality and Social Psychology, 28(2), 172-179. doi: $10.1037 / \mathrm{h} 0035716$

Mischel, W., Shoda, Y., \& Peake, P. K. (1988). The nature of adolescent competencies predicted by preschool delay of gratification. Journal of Personality and Social Psychology, 54(4), 687-696. doi: 10.1037/0022-3514.54.4.687

Mischel, W., Shoda, Y., \& Rodriguez, M. L. (1989). Delay of gratification in children. Science, 244(4907), 933-938. doi: 10.1126/science.2658056 
Navarick, D. J. (1986). Human impulsivity and choice: A challenge to traditional operant methodology. The Psychological Record, 36(3), 343-356. Retrieved from https://searchproquest-com.www2.lib.ku.edu/docview/617307177?accountid=14556

Neely, L., Rispoli, M., Camargo, S., Davis, H., \& Boles, M. (2013). The effect of instructional use of an iPad ${ }^{\circ}$ on challenging behavior and academic engagement for two students with autism. Research in Autism Spectrum Disorders, 7(4), 509-516.

doi: 10.1016/j.rasd.2012.12.004

Nevin, J. A., \& Grace, R. C. (2000). Behavioral momentum: Empirical, theoretical, and metaphorical issues. Behavioral and Brain Sciences, 23(1), 117-125. doi: $10.1017 / \mathrm{S} 0140525 \mathrm{X} 00502404$

Nevin, J. A., Mandell, C., \& Atak, J. R. (1983). The analysis of behavioral momentum. Journal of the Experimental Analysis of Behavior, 39(1), 49-59. doi: 10.1901/jeab.1983.39-49

Newquist, M. H., Dozier, C. L., \& Neidert, P. L. (2012). A comparison of the effects of brief rules, a timer, and preferred toys on self-control. Journal of Applied Behavior Analysis, 45(3), 497-509. doi: 10.1901/jaba.2012.45-497

Paglieri, F. (2013). The costs of delay: Waiting versus postponing in intertemporal choice. Journal of the Experimental Analysis of Behavior, 99(3), 362-377. doi: 10.1002/jeab.18

Patrikakou, E. N. (2016). Parent Involvement, Technology, and Media: Now What?. School Community Journal, 26(2), 9-24. Retrieved from http://www.schoolcommunitynetwork.org/SCJ.aspx

Pempek, T. A., Kirkorian, H. L., \& Anderson, D. R. (2014). The effects of background television on the quantity and quality of child-directed speech by parents. Journal of Children and Media, 8(3), 211-222. doi: 10.1080/17482798.2014.920715 
Perone, M., \& Courtney, K. (1992). Fixed-ratio pausing: Joint effects of past reinforcer magnitude and stimuli correlated with upcoming magnitude. Journal of the Experimental Analysis of Behavior, 57(1), 33-46. doi: 10.1901/jeab.1992.57-33

Pew Internet \& American Life Project (2017). Retrieved from http://www.pewinternet.org/Trend-Data-(Adults)/Device-Ownership.aspx

Prensky, M. (2001). Digital natives, digital immigrants part 1. On the Horizon, 9(5), 1-6. doi: $10.1108 / 10748120110424816$

Rachlin, H. (2000). The science of self-control. Harvard University Press, Cambridge, MA. Retrieved from https://search.proquest.com/docview/619495444?accountid=14556

Rachlin, H., \& Green, L. (1972). Commitment, choice and self-control. Journal of the Experimental Analysis of Behavior, 17(1), 15-22. doi: 10.1901/jeab.1972.17-15

Radesky, J. S., Kistin, C. J., Zuckerman, B., Nitzberg, K., Gross, J., Kaplan-Sanoff, M., ... \& Silverstein, M. (2014). Patterns of mobile device use by caregivers and children during meals in fast food restaurants. Pediatrics, 133(4), e843-e849. doi: 10.1542/peds.20133703

Radesky, J. S., Schumacher, J., \& Zuckerman, B. (2015). Mobile and interactive media use by young children: The good, the bad, and the unknown. Pediatrics, 135(1), 1-3. doi: $10.1542 /$ peds.2014-2251

Ramdoss, S., Lang, R., Mulloy, A., Franco, J., O'Reilly, M., Didden, R., \& Lancioni, G. (2011). Use of computer-based interventions to teach communication skills to children with autism spectrum disorders: A systematic review. Journal of Behavioral Education, 20(1), 55-76. doi: 10.1007/s10864-010-9112-7 
Reed, D. D., Becirevic, A., Atchley, P., Kaplan, B. A., \& Liese, B. S. (2016). Validation of a novel delay discounting of text messaging questionnaire. The Psychological Record, 66(2), 253-261. doi: 10.1007/s40732-016-0167-2

Reed, D. D., Kaplan, B. A., \& Becirevic, A. (2015). Basic research on the behavioral economics of reinforcer value. In F. D. D. Reed, \& D. D. Reed (Eds.), Autism service delivery: Bridging the gap between science and practice; autism service delivery: Bridging the gap between science and practice (pp. 279-306, Chapter xvi, 495 Pages) Springer Science + Business Media, New York, NY. Retrieved from https://search.proquest.com/docview/1752356965?accountid=14556

Retzlaff, B. J., Parthum, E. T. P., Pitts, R. C., \& Hughes, C. E. (2017). Escape from rich-to-lean transitions: Stimulus change and timeout. Journal of the Experimental Analysis of Behavior, 107(1), 65-84. doi: 10.1002/jeab.236. Retrieved from https://search.proquest.com/docview/1859064519?accountid=14556

Reynolds, B., \& Schiffbauer, R. (2005). Delay of gratification and delay discounting: A unifying feedback model of delay-related impulsive behavior. The Psychological Record, 55(3), 439-460. Retrieved from https://search.proquest.com/docview/620853731?accountid=14556

Ribner, A., Fitzpatrick, C., \& Blair, C. (2017). Family socioeconomic status moderates associations between television viewing and school readiness skills. Journal of Developmental and Behavioral Pediatrics, 38(3), 233-239.

doi: 10.1097/DBP.0000000000000425 
Rideout, V. J., \& Hamel, E. (2006). The media family: Electronic media in the lives of infants, toddlers, preschoolers and their parents. Menlo Park: Henry J. Kaiser Family Foundation. Retrieved December 7, 2017, from http://www.kff.org.

Rideout, V. (2011). Zero to eight. Common Sense Media, 48. Retrieved December 7, 2017, from http://www.commonsensemedia.org/sites/default/files/research/zerotoeightfinal2011.pdf

Ross, S. T., Dowda, M., Saunders, R., \& Pate, R. (2013). Double dose: The cumulative effect of TV viewing at home and in preschool on children's activity patterns and weight status. Pediatric Exercise Science, 25(2), 262-272. doi: 10.1123/pes.25.2.262

Schweitzer, J. B., \& Sulzer-Azaroff, B. (1988). Self-control: Teaching tolerance for delay in impulsive children. Journal of the Experimental Analysis of Behavior, 50(2), 173-186. doi: $10.1901 /$ jeab.1988.50-173

Shoda, Y., Mischel, W., \& Peake, P. K. (1990). Predicting adolescent cognitive and selfregulatory competencies from preschool delay of gratification: Identifying diagnostic conditions. Developmental Psychology, 26(6), 978-986. doi: 10.1037/0012-1649.26.6.978

Shuler, C., (2012). iLearn II: an analysis of the education category of apple's app store. The Joan Ganz Cooney Center at Sesame Workshop. Retrieved from http://www.joanganzcooneycenter.org/wp-content/uploads/2012/01/ilearnii.pdf

Sonuga-Barke, E., Lea, S. E., \& Webley, P. (1989). Children's choice: Sensitivity to changes in reinforcer density. Journal of the Experimental Analysis of Behavior, 51(2), 185-197. doi:10.1901/jeab.1989.51-185

Sonuga-Barke, E., Lea, S. E., \& Webley, P. (1989). The development of adaptive choice in a self-control paradigm. Journal of the Experimental Analysis of Behavior, 51(1), 77-85. doi:10.1901/jeab.1989.51-77 
Staddon, J.E.R., \& Simmelhag, V.L. (1971). The "superstition experiment: A reexamination of Its implications for the principles of adaptive behavior. Psychological Review, 78(1), 3-43. doi: $10.1037 / \mathrm{h} 0030305$

Tandon, P. S., Zhou, C., Sallis, J. F., Cain, K. L., Frank, L. D., \& Saelens, B. E. (2012). Home environment relationships with children's physical activity, sedentary time, and screen time by socioeconomic status. The International Journal of Behavioral Nutrition and Physical Activity, 9, 9. doi:10.1186/1479-5868-9-88

Trosclair-Lasserre, N., Lerman, D. C., Call, N. A., Addison, L. R., \& Kodak, T. (2008). Reinforcement magnitude: An evaluation of preference and reinforcer efficacy. Journal of Applied Behavior Analysis, 41(2), 203-220. doi: 10.1901/jaba.2008.41-203

Vollmer, T. R., Borrero, J. C., Lalli, J. S., \& Daniel, D. (1999). Evaluating self-control and impulsivity in children with severe behavior disorders. Journal of Applied Behavior Analysis, 32(4), 451-466. doi:10.1901/jaba.1999.32-451

Whiting, S. W., \& Dixon, M. R. (2015). Delayed reinforcement and self-control: Increasing tolerance for delay with children and adults with autism. In F. D. D. Reed, \& D. D. Reed (Eds.), Autism service delivery: Bridging the gap between science and practice; autism service delivery: Bridging the gap between science and practice (pp. 407-435, Chapter xvi, 495 Pages) Springer Science + Business Media, New York, NY. Retrieved from https://search.proquest.com/docview/1752357358?accountid=14556 
Williams, D. (2015). Challenging behaviors and task transitions in autism: Translating clinical phenomenology and basic behavioral process. In F. D. D. Reed, \& D. D. Reed (Eds.), Autism service delivery: Bridging the gap between science and practice; autism service delivery: Bridging the gap between science and practice (pp. 113-150, Chapter xvi, 495 Pages) Springer Science + Business Media, New York, NY. Retrieved from https://search.proquest.com/docview/1752356601?accountid=14556

Williams, D. C., Saunders, K. J., \& Perone, M. (2011). Extended pausing by humans on multiple fixed-ratio schedules with varied reinforcer magnitude and response requirements.

Journal of the Experimental Analysis of Behavior, 95(2), 203-220.

doi:10.1901/jeab.2011.95-203 
Figures

Competing

Reinforcer Assessment
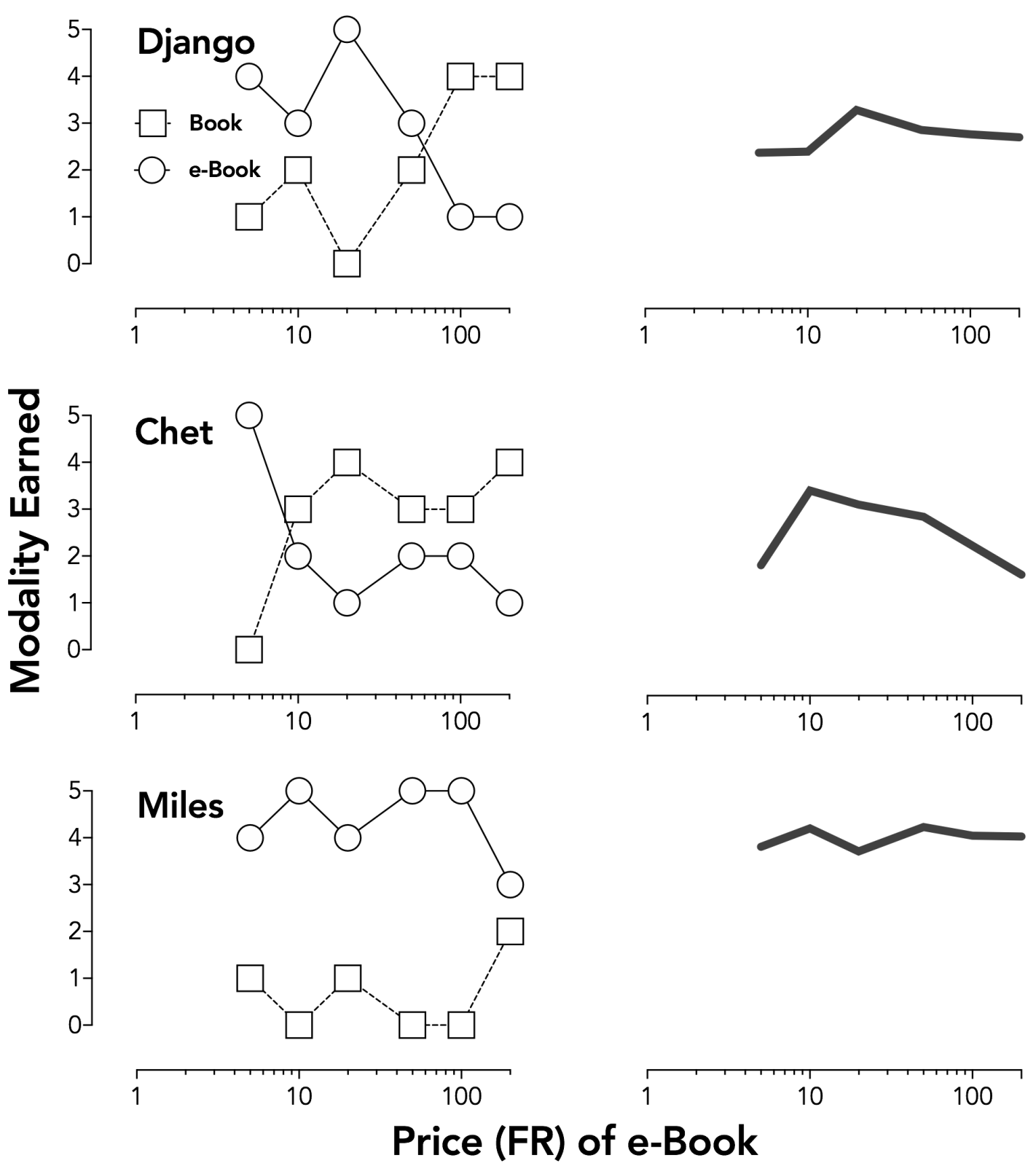

Rate of FR Responding for e-Book
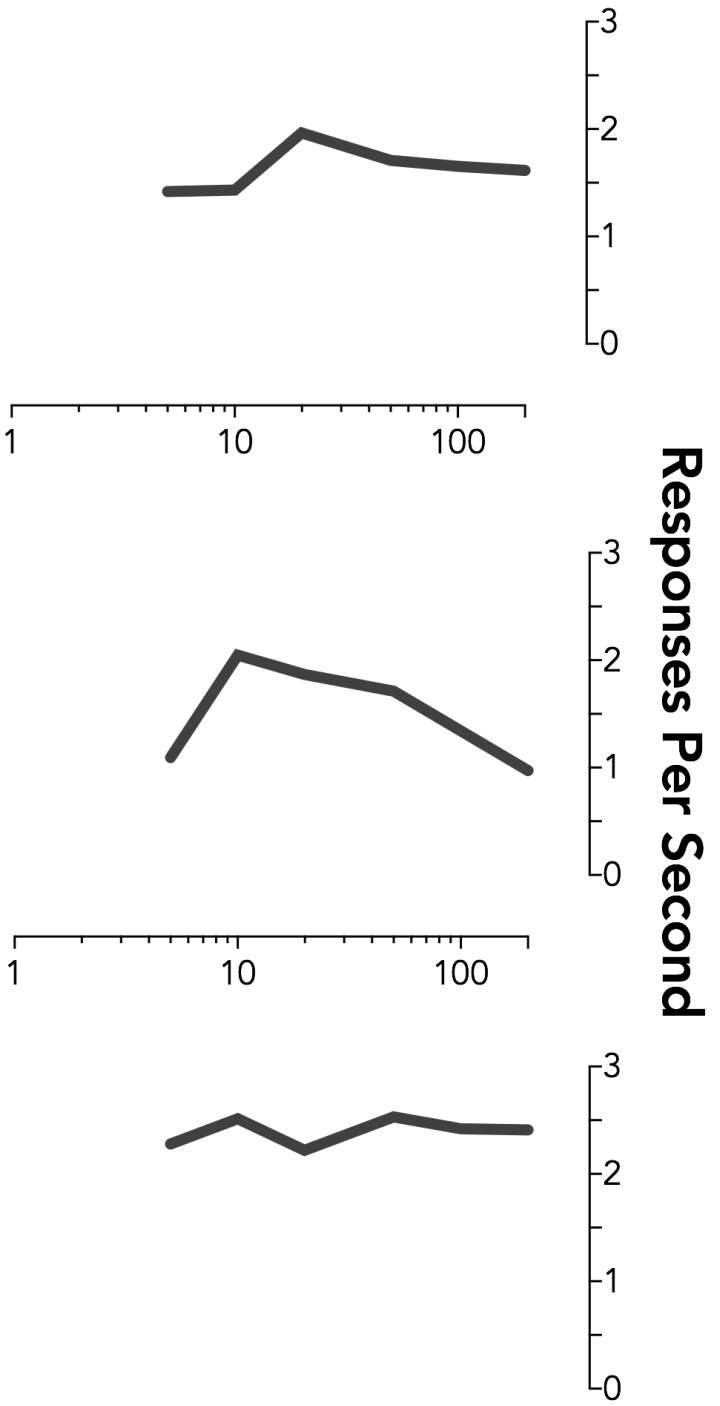

Figure 1. Left panels: The number of times participants chose the print book (FR-1 across sessions) and the e-book (increasing price across sessions). Right panels: The rate of button-presses while meeting the FR price of the e-book. 
Original Definition
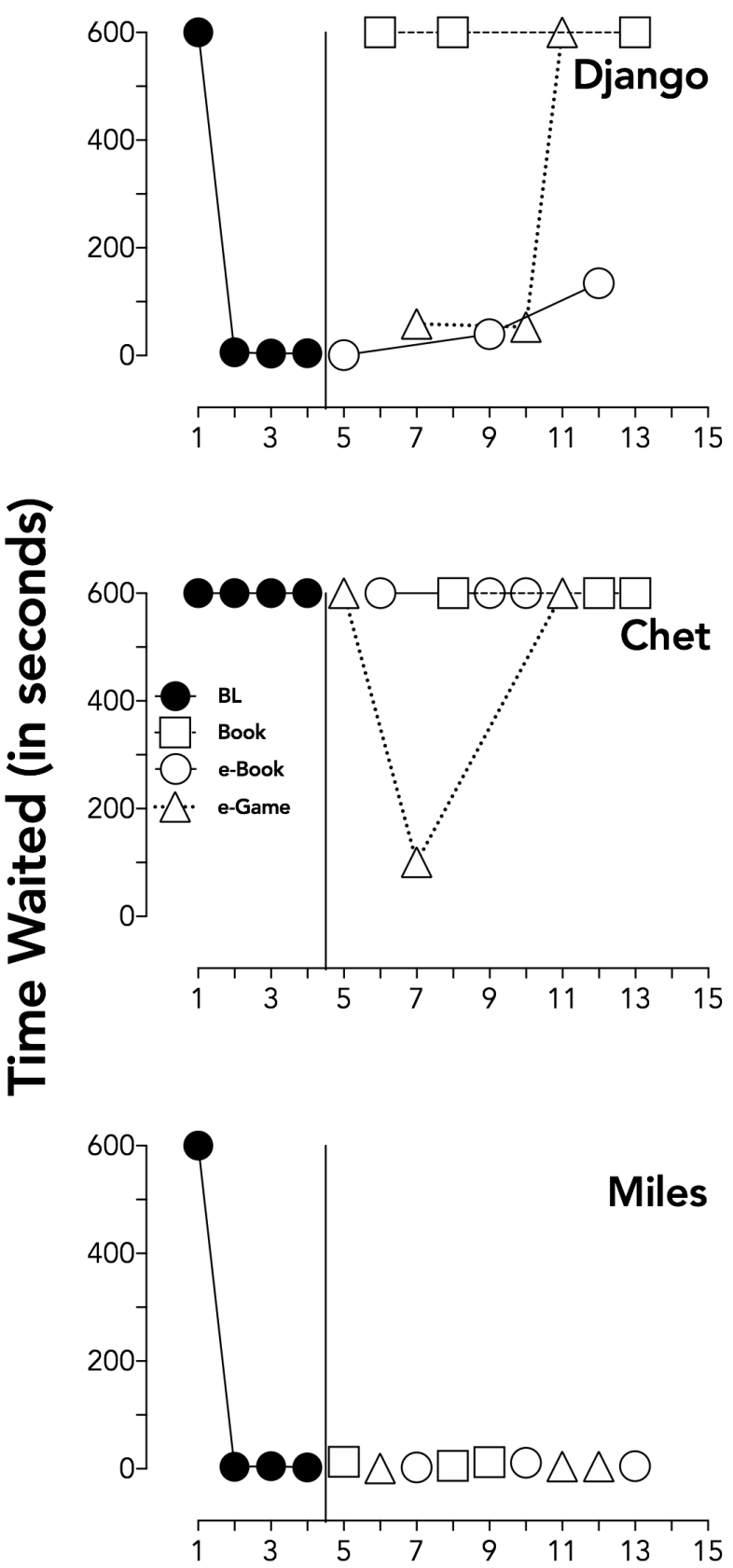

\section{Revised Definition}
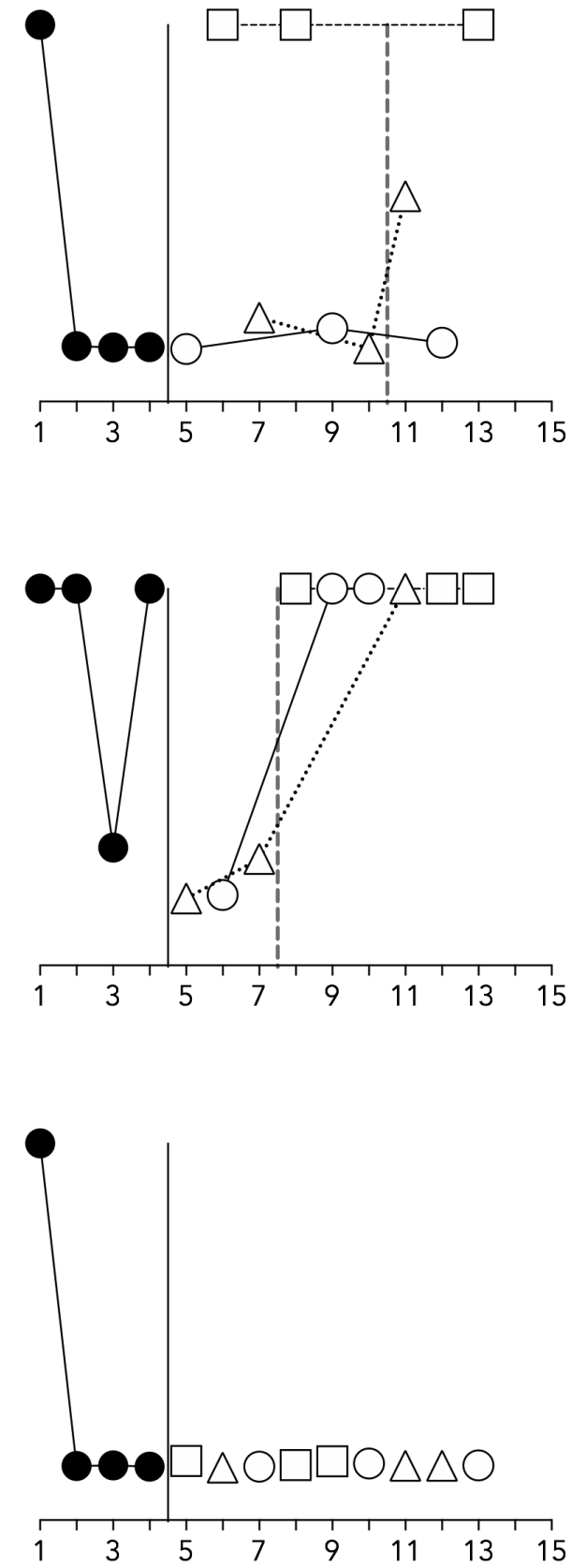

\section{Sessions}

Figure 2. Left panels: Delay of gratification in Baseline and following 5 min exposure to Book, e-Book, and e-Game conditions. Consumption here is defined as eating the entire edible reinforcer. Right panels: Delay of gratification during the same sessions as the left panels with consumption defined as any part of the edible passing the lips or making contact with the participants' tongue. Broken phase change lines indicate when participants were informed of the revised definition of consumption. 
Competing

Reinforcer Assessment
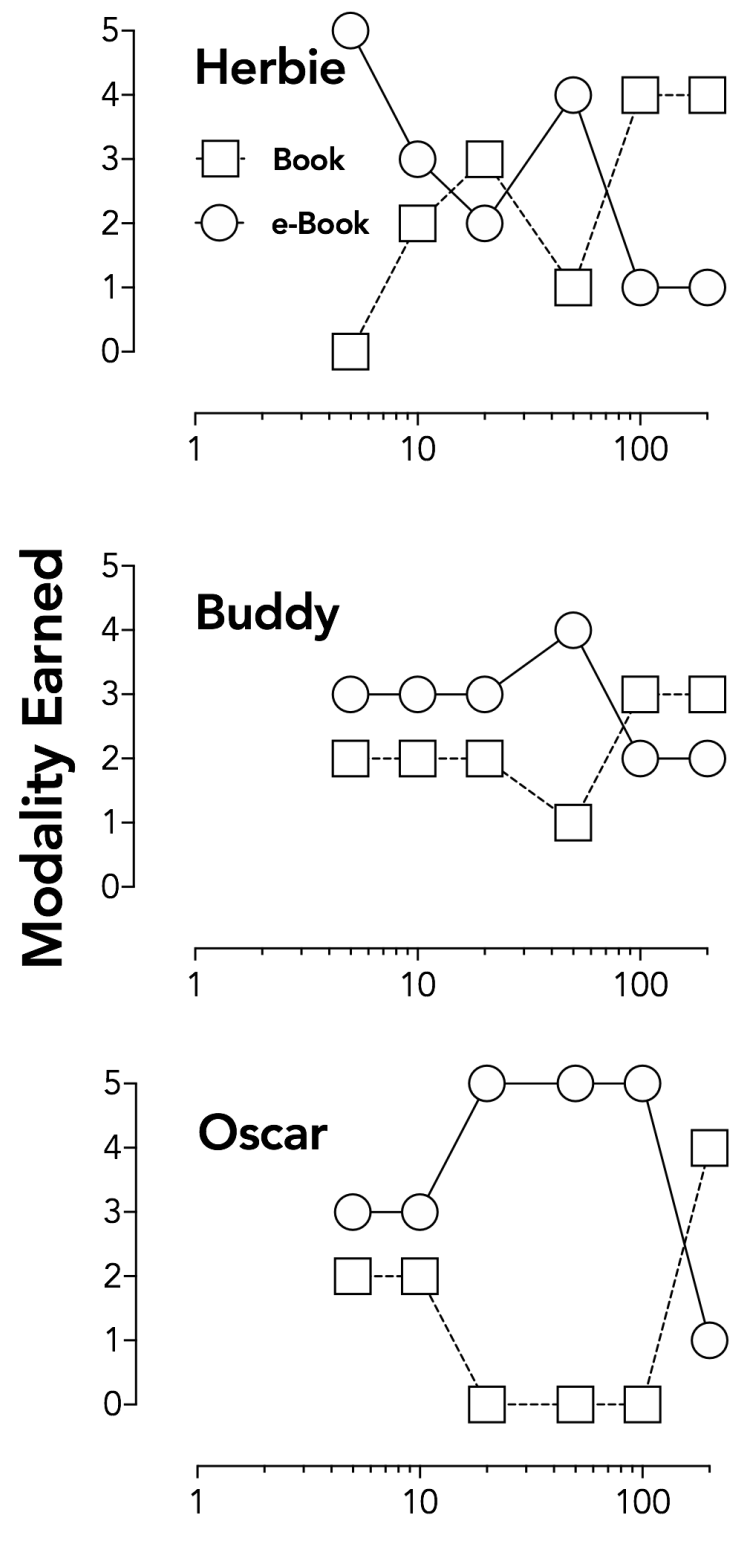

Rate of FR Responding for e-Book
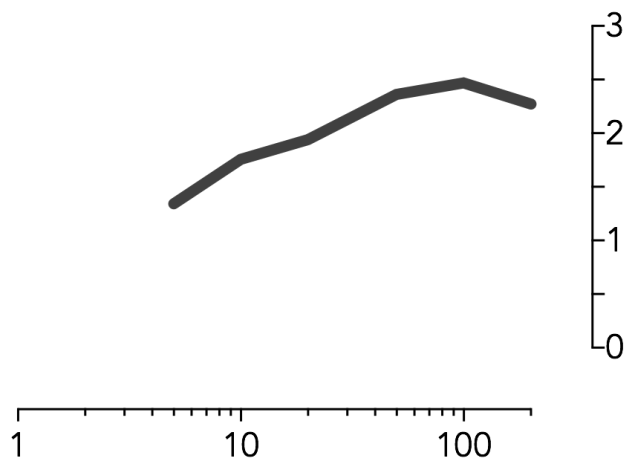

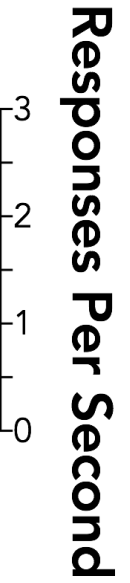

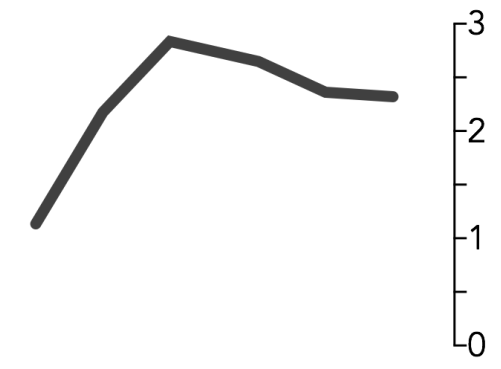

Figure 3. Left panels: The number of times participants chose the print book (FR1 across sessions) and the e-book (increasing price across sessions). Right panels:

The rate of button-presses while meeting the FR price of the e-book. 


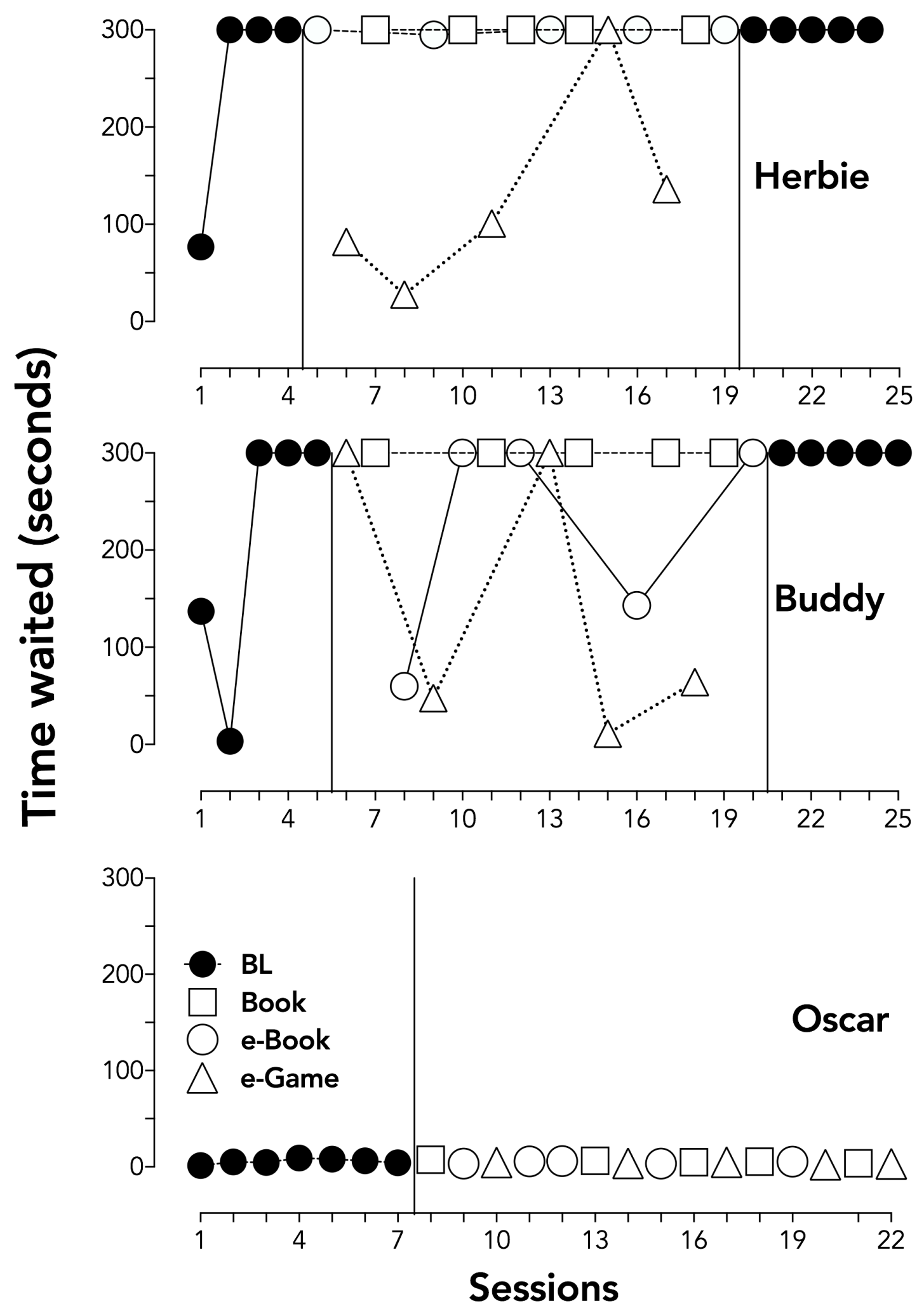

Figure 4. Delay of gratification in Baseline and following 5-min exposure to the Book, e-Book, and e-Game conditions. Consumption is defined as any part of the edible passing the lips or making contact with the participants' tongue. 


\title{
Appendix
}

\author{
Applied Behavioral Sciences \\ University of Kansas \\ Lawrence, KS 66045
}

Dear parent/guardian,

My graduate-student teaching assistants and I are interested in how preschool-age children delay gratification (i.e., wait for what they want) immediately after using an iPad. The purpose of this study is to (a) evaluate children's preference for a print versus an electronic picture book and (b) compare delay of gratification wait times (i.e., the Marshmallow Test) immediately after looking at a printed picture book, an e-Book, or after playing an interactive iPad game This study may help your child indirectly in that we may identify that s/he makes a more "self-controlled" choice after either print or screen media. Additionally, it may inform us of the degree to which your child values print media relative to screen media.

If you agree to have your child as a participant in this study, we will conduct an assessment to determine the type of image themes your child prefers (e.g., dinosaurs; popular cartoon characters) as well as your child's relative preference for a print and an e-Book. We let your child interact with either a print book, an e-Book, or an iPad game for 5 minutes a day. After the 5 minute period, we will give your child the option of having a small treat (piece of candy or a chip) right away, or two pieces after several minutes of waiting (i.e., delaying gratification).

This study will involve multiple sessions. If you agree for your child to be in the study, he or she will work with us several days a week for a period lasting from several weeks to a month. The time we work with your child will be determined by your child's schedule. The time selected will be a time of day that is least disruptive to your child's current schedule for learning opportunities. If you choose not to enroll your child in this research, it will not prevent or affect other educational services he/she may receive.

The confidentiality of you and your child will be protected to the fullest extent of the law. You and your child will be assigned code names or numbers at the start of the study. The information linking your personal information to your code name will be kept in a locked room and will only be accessible by the research team.

You and your child have the right to withdraw consent at any time, without penalty. The benefits of this study are that we may (a) determine your child's relative preference for print versus screen media and (b) discover if the type of media your child uses contributes to subsequent performance on a delay of gratification task. There is no compensation for participating in this study. Your child's progress in this study will be provided to you on a weekly basis. If you have any questions about this study, please contact Dr. Derek Reed at (785) 864-0504.

Thank you for your time,

Derek D. Reed, Ph.D., BCBA-D, LBA

Gideon P. Naudé

Lead Researcher

\section{Appendix 1. Recruitment letter explaining the present investigation to parents/caregivers.}


Task Analysis for Scoring e-Book Demand Sessions

Scoring the Videos

You will code the following in your individual Excel scoring files ( 1 for "Yes"; 0 for "No"):

- Forced choice at start of session: Record a 1 if the first trial features the e-Book and the book by themselves (i.e., only one image is on the screen; once for the e-Book and once for the book). Score a " 0 " if the first trial features BOTH the iPad and the book.

- Instructions before each trial: Record a 1 if the experimenter provides complete instructions (i.e., pointing to the images and/or buttons). Score a " 0 " if you don't see me do this.

- Note: Still score a 1 if the participant responds while the experimenter is still giving the instructions.

- Correct modality delivered at blackout: After the participant meets the response requirement, the computer screen will go black. Score a 1 if the experimenter presents the child the correct modality (i.e., the item chosen by responding on the corresponding button). Score a " 0 " if the experimenter presents the unchosen modality or does not present a modality.

- Modality removed after blackout: Score a 1 if the experimenter takes back the modality when the choice screen reappears. Score a " 0 " if the modality remains with the participant.

Appendix 2. Procedural fidelity task analysis for scoring the e-book demand videos. 
Task Analysis for Scoring Delay of Gratification Sessions

Scoring the Videos

You will code the following in your individual Excel scoring files ( 1 for "Yes"; 0 for "No"):

- Provides modality: Record a 1 if the experimenter provides the participant either a book or an iPad

- Note: Participants do not receive a modality in baseline (BL) conditions; these will already be marked with "NA" in your sheets.

- Presents edible: Record a 1 if I give the experimenter provides the participant an edible after the (book/iPad) exposure period (for BL just put a 1 if the child receives the edible)

- Presents edible on a plate: Record a 1 if the edible is on a plate ( 0 if the edible is not)

- Instructions: Record a 1 if the experimenter provides the instructions for the delay of gratification trial.

- Time waited: start the timer as the experimenter says the last word of the instructions "... and I'll give you TWO"

- Initiate the timer as the experimenter says the word "TWO"

- Stop the timer as soon as the edible makes contact with the child's lips, or tongue

- Note: picking a piece off of the edible and putting it to the lips or tongue counts as consuming the edible, so you would stop the timer for that.

- Licking fingers after touching the edible does NOT count.

- Provides 2 edibles only if child waits whole duration:

○ without tasting/eating the edible

- Note: On two sessions "Chet" will receive the LLR despite having licked it during the delay. This was prior to the revised definition of consumption.

\section{Appendix 3. Timing and procedural fidelity task analysis for scoring the delay of gratification sessions.}




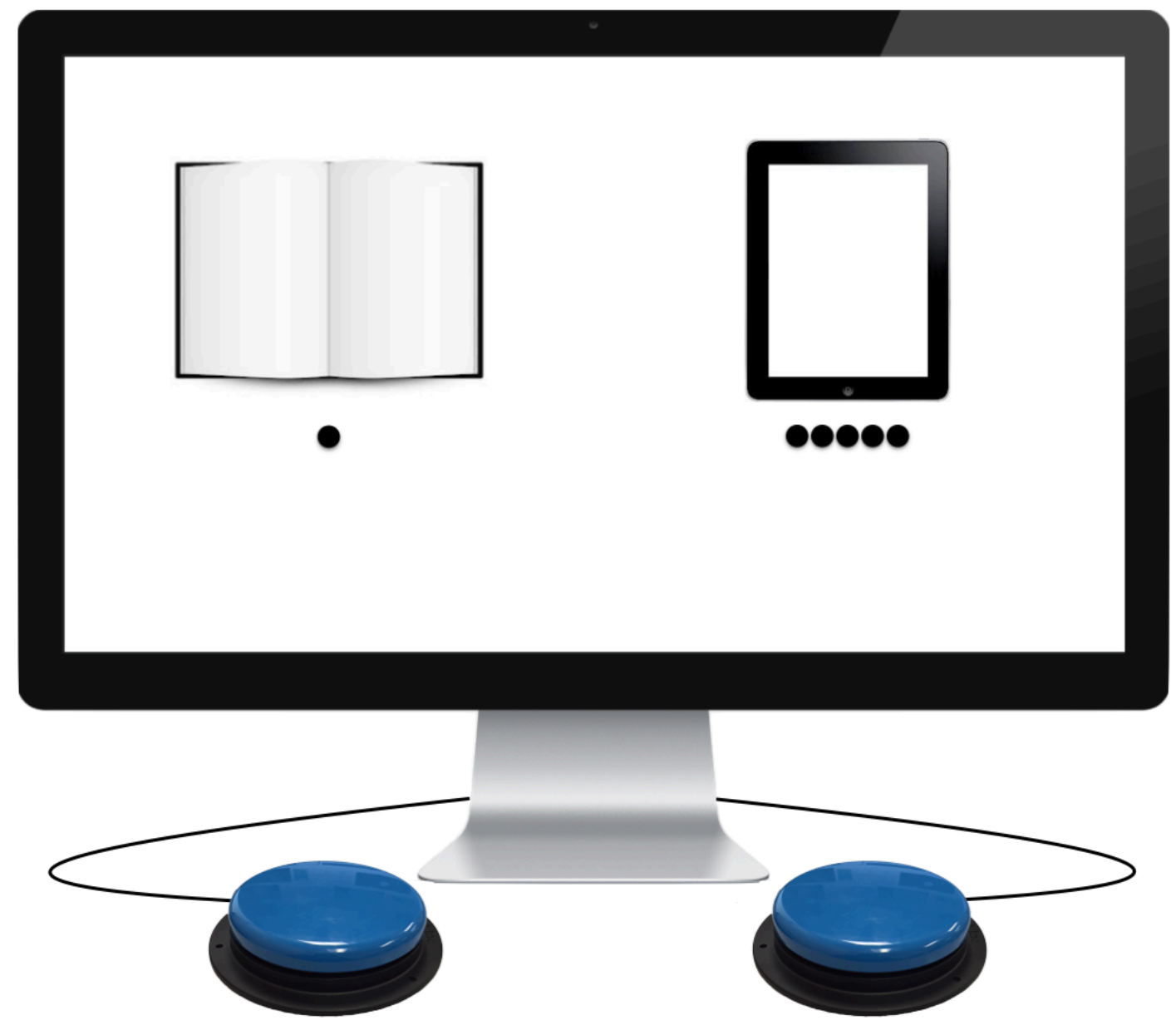

Appendix 4. Experimental preparation for CRA. Response buttons corresponded with modality on matching side of screen. 


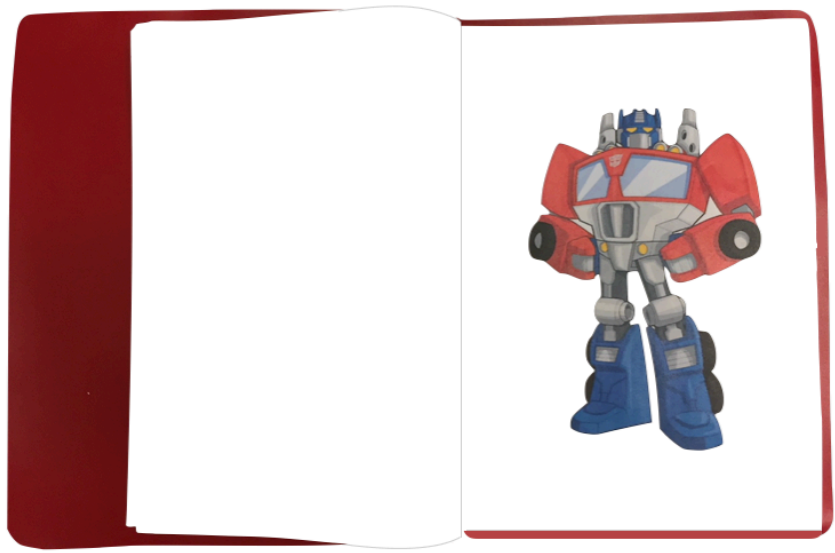

\section{Print Book}

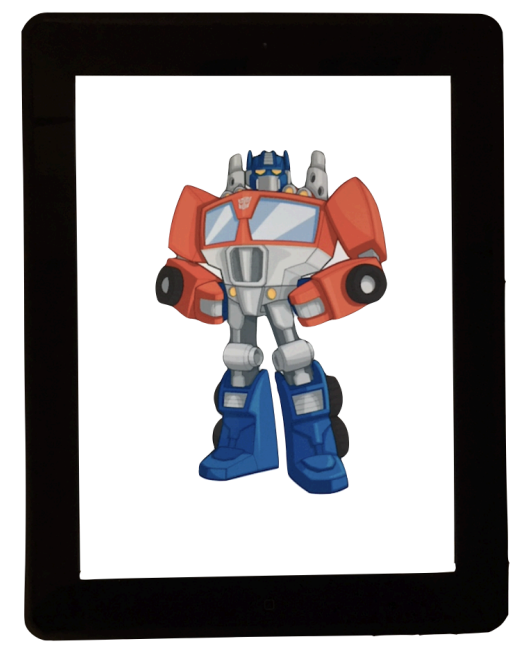

\section{e-Book}

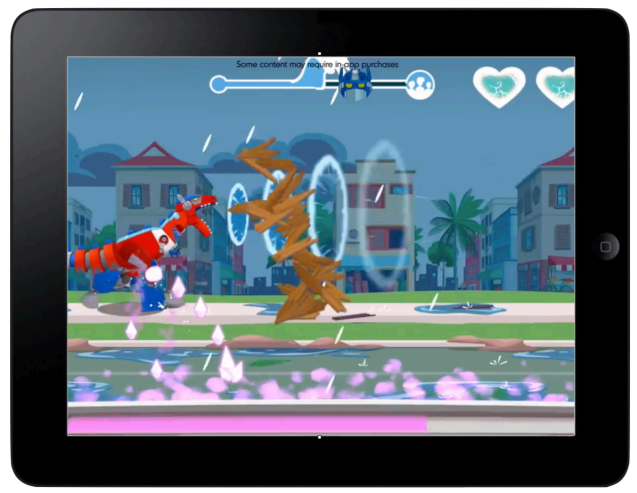

e-Game

Appendix 5. Stimuli for CRA (print book and e-book) and Delay of Gratification sessions (print book, e-book, and e-game). 